\title{
Activation of Pedunculopontine Tegmental Protein Kinase A: A Mechanism for Rapid Eye Movement Sleep Generation in the Freely Moving Rat
}

\author{
Ram S. Bandyopadhya, Subimal Datta, and Subhash Saha \\ Sleep and Cognitive Neuroscience Laboratory, Department of Psychiatry, Boston University School of Medicine, Boston, Massachusetts 02118
}

\begin{abstract}
Cells in the pedunculopontine tegmentum (PPT) play a key role in the generation of rapid eye movement (REM) sleep, but its intracellular signaling mechanisms remain unknown. In the current studies, the role of PPT intracellular protein kinase A (PKA) in the regulation of REM sleep was evaluated by comparing PKA subunit [catalytic $\left(\mathrm{PKA}_{\mathrm{C} \alpha}\right)$ and regulatory $\left(\mathrm{PKA}_{\mathrm{RI}}, \mathrm{PKA}_{\mathrm{RII} \alpha}\right.$, and $\left.\mathrm{PKA}_{\mathrm{RII} \beta}\right)$ types] expression and activity in the PPT at normal, high, and low REM sleep conditions. To compare anatomical specificity, REM sleep-dependent expressions of these PKA subunits were also measured in the medial pontine reticular formation (mPRF), medial prefrontal cortex (mPFC), and anterior hypothalamus (AHTh). The results of these PKA subunit expression and activity studies demonstrated that the expression of $\mathrm{PKA}_{\mathrm{C} \alpha}$ and PKA activity in the PPT increased and decreased during high and low REM sleep, respectively. Conversely, $\mathrm{PKA}_{\mathrm{C} \alpha}$ expression and PKA activity decreased with high REM sleep in the mPRF. Expression of PKA $\mathrm{C}_{\alpha}$ also decreased in the mPFC and remained unchanged in the AHTh with high REM sleep. These subunit expression and PKA activity data reveal a positive relationship between REM sleep and increased PKA activity in the PPT. To test this molecular evidence, localized activation of cAMP-dependent PKA activity was blocked using a pharmacological technique. The results of this pharmacological study demonstrated that the localized inhibition of cAMP-dependent PKA activation in the PPT dose-dependently suppressed REM sleep. Together, these results provide the first evidence that the activation of the PPT intracellular PKA system is involved in the generation of REM sleep.
\end{abstract}

Key words: REM sleep; signal transduction; pedunculopontine tegmentum; medial pontine reticular formation; medial prefrontal cortex; anterior hypothalamus

\section{Introduction}

Rapid eye movement (REM) sleep is a distinctive sleep stage that alternates with episodes of slow-wave sleep (SWS). A number of studies in both humans and animals suggest that the expression of REM sleep is critical for the development, maturation, and plasticity of the mammalian brain (for review, see Smith, 1995; Hobson and Pace-Schott, 2002; Datta and Patterson, 2003). Despite the functional significance of REM sleep, our understanding of the mechanisms of REM sleep generation remains incomplete. Over the last decade, considerable progress has been made in identifying the brain regions and cell types whose activation is shown to be critical for the generation of REM sleep (for review, see Pace-Schott and Hobson, 2002). Specific regions of the brainstem, including the pedunculopontine tegmentum (PPT) cholinergic cells and medial pontine reticular formation (mPRF) gluta-

\footnotetext{
Received Feb. 20, 2006; revised July 6, 2006; accepted July 25, 2006.

This work was supported by National Institutes of Health Grants MH59839 and NS34004 (S.D.). We thank Jagadish Ulloor, Robert Ross MacLean, and Melissa Burgos for technical assistance. I (S.D., senior and corresponding author) dedicate this publication to my mentor, the late Prof. M. Steriade, who taught me how to record single-cell activity of thalamically projecting cholinergic cells in the PPT/LDT of behaving cats.

Correspondence should be addressed to Dr. Subimal Datta, Sleep and Cognitive Neuroscience Laboratory, Department of Psychiatry, M-902, Boston University School of Medicine, 85 East Newton Street, Boston, MA 02118. E-mail: subimal@bu.edu.

DOI:10.1523/JNEUROSCI.2173-06.2006

Copyright $\odot 2006$ Society for Neuroscience $\quad$ 0270-6474/06/268931-12\$15.00/0
}

matergic cells, have been identified as the most important structures and cell types for the generation of REM sleep (Steriade and McCarley, 1990; Steriade et al., 1990; Datta, 1995; Garcia-Rill et al., 2001; Datta and Siwek, 2002; Jones, 2004; McCarley, 2004). More recently, it has also been shown that impaired REM sleep in Alzheimer's disease is attributable to the degeneration of PPT cholinergic cells (Zhang et al., 2005). Despite tremendous progress in the identification of brain regions, specific neurotransmitters, and receptors involved in the generation of REM sleep, the roles of specific intracellular signal transduction mechanisms in REM sleep generation remain to be identified.

Recent studies have demonstrated that the activation of PPT cholinergic cells by kainate receptors induces REM sleep and increases REM sleep-specific neuronal activities, whereas the activation of $G_{A B A}$ receptors suppresses REM sleep and REM sleep-specific extracellular activities (Datta, 2002; Datta et al., 2002; Ulloor et al., 2004). It has also been demonstrated that the inhibition of adenylyl cyclase (AC) activity in the PPT suppresses REM sleep (Datta and Prutzman, 2005). Because both kainate and $\mathrm{GABA}_{B}$ receptors and $\mathrm{AC}$ activation could involve the cAMP-dependent PKA signaling pathway (Gilman, 1987; Sivilotti and Nistri, 1991; Wang et al., 1993; Couve et al., 2000; Marinissen and Gutkind, 2001), we hypothesized that the intracellular PKA system in the PPT may be involved in the regulation of physiological REM sleep. To test this hypothesis, the first study 
quantified different subunit levels of PKA in different regions of the brain at different levels of REM sleep. In the second study, wake-sleep signs were examined after a control vehicle or an inhibitor of cAMP-dependent PKA activation was microinjected into the PPT.

\section{Materials and Methods}

Subjects. Experiments were performed on 56 adult male Wistar rats (Charles River Laboratories, Wilmington, MA) weighing between 200 and $300 \mathrm{~g}$. The rats were housed individually at $24^{\circ} \mathrm{C}$ with ad libitum access to food and water. Lights were on from 7:00 A.M. to 7:00 P.M. (light cycle) and off from 7:00 P.M. to 7:00 A.M. (dark cycle). The principles for the care and use of laboratory animals in research, as outlined by the National Institutes of Health Guide for the Care and Use of Laboratory Animals, were strictly followed.

Surgical procedures for electrode and guide tube implantation. All surgical procedures were performed stereotaxically under aseptic conditions and were in accordance with the guidelines approved by the institutional animal care and use committee (protocol AN-14084). Animals were anesthetized with pentobarbital $(40 \mathrm{mg} / \mathrm{kg}$, i.p.; Abbott Laboratories, Chicago, IL), placed in the stereotaxic apparatus, and secured using blunt rodent ear bars as described previously (Paxinos and Watson, 1997). The appropriate depth of anesthesia was judged by the absence of palpebral reflexes and the absence of a response to tail pinch. Core body temperature was maintained at $37 \pm 1^{\circ} \mathrm{C}$ with a thermostatic heating pad and a rectal thermister probe. The scalp was cleaned and painted with povidone iodine. A scalp incision was made, and the skin was retracted. The skull surface was cleaned in preparation for electrode implantation. After completion of the surgical procedure, animals were administered saline (5 cc, s.c.) to prevent dehydration and ampicillin (50 mg per rat, i.m.; Bristol-Myers Squibb, Princeton, NJ) to control any potential postsurgical infection. Potential postoperative pain was controlled with buprenorphine $(0.05 \mathrm{mg} / \mathrm{kg}$, s.c.; Abbott Laboratories).

To record the behavioral states of vigilance, cortical electroencephalogram (EEG), dorsal neck muscle electromyogram (EMG), electrooculogram (EOG), hippocampal EEG (to record theta wave), and pontine EEG (to record pontine wave) recording electrodes were chronically implanted as described previously (Datta, 2000, 2002; Datta et al., 2002). In addition to these electrodes, 35 rats had a stainless steel guide tube (26 gauge), with an equal-length stylet inside, stereotaxically implanted 2 $\mathrm{mm}$ above the PPT (in relation to stereotaxic " 0 ": anterior, $1.0 \mathrm{~mm}$; lateral, $1.8 \mathrm{~mm}$; and horizontal, $3.0 \mathrm{~mm}$ ) as described previously (Datta, 2002; Datta et al., 2002). All electrodes and guide tube were secured to the skull with dental acrylic. Electrodes were crimped to miniconnector pins and brought together in a plastic connector. Immediately after surgery, animals were placed in recovery cages and monitored for successful recovery from anesthesia and surgery. Successful recovery was gauged by the return of normal postures, voluntary movement, and grooming.

Adaptation recording session. After the postsurgical recovery period of 3-7 d, rats were habituated to the experimenter, the sound-attenuated recording cage (electrically shielded; $76.2 \times 45.72 \times 45.72 \mathrm{~cm}$ ), and free-moving polygraphic (Grass polygraph, model 79; Grass Instruments, Quincy, MA) recording conditions for 7-10 d. The last day of these adaptation recording sessions was determined when, for 3 consecutive days, the day-to-day variation of the percentage of REM sleep was $<5 \%$ of the rats' total amount of REM sleep. All adaptation-recording sessions were performed between 9:00 A.M. and 4:00 P.M., when rats are normally sleeping. During recovery, habituation, and free-moving recording conditions (adaptation recording sessions), all rats were housed under the same $12 \mathrm{~h}$ light/dark cycle with ad libitum access to food and water.

Polygraphic recordings and REM sleep deprivation setup. To record cortical EEG, EMG, EOG, hippocampal EEG, and pontine EEG in a freely moving condition, each rat's head plug was mated to a male connector that was in turn connected to a commutator. Signals from this commutator were sent to a polygraph (Grass model 79; located in the next room) via the electrode board (located inside the recording chamber). To allow rats to move freely inside the recording cage while maintaining the head plug connection, a counterbalanced connecting cable and a mechanical pulley system (attached to the roof of the recording chamber) were used. In a separate room, polygraphic signs of the rat were continuously observed on a computer monitor to identify ongoing behavioral stages (Datta and Siwek, 2002; Ulloor et al., 2004).

For the purpose of REM sleep deprivation, the beginning of each REM sleep episode was identified by observation of ongoing polygraphic records. From the room adjacent to the rat, the experimenter pressed a mechanical lever within 2-3 s of REM sleep onset, the animal's head was gently lifted, and the animal was awakened. The detailed description and validation of this selective REM sleep deprivation method was described previously (Datta et al., 2004). One of the most important advantages of this REM sleep deprivation method is that this method successfully eliminates $>75 \%$ of REM sleep without significantly reducing SWS.

Determination of behavioral states. For the purpose of determining possible effects on sleep and wakefulness $(\mathrm{W})$, polygraphic data were captured on-line with a computer using Gamma software (Grass product group; Astro-Med, West Warwick, RI). From this captured data, three behavioral states were distinguished and scored visually using Rodent Sleep Stager software (Grass product group; Astro-Med). These three states were W, SWS, and REM sleep. The physiological criteria for the identification of these wake-sleep states were described in detail previously (Datta et al., 2002, 2004). In the first study, which focused on PKA subunit analysis, the behavioral states of W, SWS, and REM sleep were scored in successive $5 \mathrm{~s}$ epochs. This epoch length allowed us to quantify the short periods of REM sleep (3-5s) in the rats in which REM sleep was selectively terminated (Datta et al., 2004). In the second study, however, which focused on determining possible effects of Rp-adenosine $3^{\prime}, 5^{\prime}$ cyclic monophosphothioate triethylamine (cAMPS) on sleep and wakefulness, the behavioral states of W, SWS, and REM sleep were scored in successive $10 \mathrm{~s}$ epochs.

Drug and vehicle for microinjections. The drug used in the second study was a specific membrane-permeable inhibitor of cAMP-dependent PKA activation, Rp-cAMPS (molecular weight, 446.46), purchased from Sigma (St. Louis, MO). The Rp-cAMPS was dissolved in $0.9 \%$ saline to make four different doses $(0.28,0.55,1.1$, and $2.2 \mathrm{nmol} / 100 \mathrm{nl})$. This $0.9 \%$ saline $(100 \mathrm{nl})$ was also used for the vehicle control microinjection. Control saline and drug solutions were freshly prepared under sterile conditions before each use. The selection of this drug was based on the selective inhibitory effect on intracellular cAMP-PKA activation (Van Haastert et al., 1984; Wang et al., 1991; Shi and Bunney, 1992). This commercially available Rp-cAMPS is suitable for our local microinjection studies because it is water soluble, cell permeable, has reversible effects, and has been used successfully for microinjection studies in behaving animals (Cook et al., 1995; Self and Nestler, 1995; Capece and Lydic, 1997; Punch et al., 1997; Self et al., 1998; Schafe and LeDoux, 2000).

Tissue collection and Western blotting for the quantification of PKA subunits. After the rats were killed with $\mathrm{CO}_{2}$, the brains were rapidly removed and quickly chilled with dry ice. These frozen brains were cut in the transverse plane in $300-\mu \mathrm{m}$-thick sections with the use of a Vibratome (series 3000; Technical Products International, St. Louis, MO). Then, under a dissecting microscope, the medial prefrontal cortex (mPFC), anterior hypothalamus (AHTh), PPT, and mPRF were dissected separately on an ice-chilled Petri dish. The dissected tissues from these four specific brain areas, containing tissues from both the left and right sides of the brain, of each individual rat were stored separately in prechilled microcentrifuge tubes at $-80^{\circ} \mathrm{C}$ until assayed. As a result, levels of each PKA subunit were measured in each specific brain area using tissue collected from both hemispheres. Following are the descriptions for the spatial and anatomical areas of the brain (Paxinos and Watson, 1997) from which these tissues were collected. The mPFC tissue collection area: anteroposterior, between 2 and $4 \mathrm{~mm}$ anterior to the bregma; mediolateral, between midline and $2 \mathrm{~mm}$ lateral; dorsoventral, between dorsal surface and $3 \mathrm{~mm}$ deep from the surface. Anatomically, this area includes cingulate cortex (areas 1 and 2) and frontal cortex (area 2). The AHTh tissue collection area: anteroposterior, between 0.2 and 2.2 $\mathrm{mm}$ posterior to the bregma; mediolateral, between midline and $2 \mathrm{~mm}$ lateral; dorsoventral, between anterior commissure and optic chiasm. 
Anatomically, this area includes preoptic-anterior hypothalamus and a part of the lateral hypothalamus. The PPT tissue collection area: anteroposterior, between 7.7 and $8.7 \mathrm{~mm}$ posterior to the bregma; mediolateral, between 1.5 and $2.5 \mathrm{~mm}$ lateral to the midline; dorsoventral, between 5.5 and $6.5 \mathrm{~mm}$ from the dorsal surface of the brain. Anatomically, this area includes mainly the PPT. The mPRF tissue collection area: anteroposterior, between $7.7 \mathrm{~mm}$ and $8.7 \mathrm{~mm}$ posterior to the bregma; mediolateral, between 0.5 and $1.5 \mathrm{~mm}$ lateral to the midline; dorsoventral, between 7.0 and $8.0 \mathrm{~mm}$ from the dorsal surface of the brain. Anatomically, this area includes only the oral part of the pontine reticular nucleus.

The individual frozen tissue samples were rapidly sonicated (Sonic Dismembrator, model 100; Fisher Scientific, Pittsburgh, PA) in five volumes (w/v) of ice-cold mammalian CelLytic buffer (Sigma). The homogenates were then centrifuged at $10,000 \mathrm{rpm}$ for $10 \mathrm{~min}$ at $4^{\circ} \mathrm{C}$. The amount of protein in the supernatant (soluble fraction) of individual samples was then measured using Bradford's method (Bradford, 1976). Protein $\left(\sim 25 \mu \mathrm{g}\right.$ ) from each sample was heated (for $3 \mathrm{~min}$ at $95^{\circ} \mathrm{C}$ ) in Laemmli's $1 \times$ protein loading buffer (Laemmli, 1970). These denatured samples were then loaded onto $12 \%$ SDS-polyacrylamide gels and resolved by standard electrophoresis in the Tris-glycine-SDS buffer, $\mathrm{pH} 8.3$ (containing $25 \mathrm{~mm}$ Tris base, $192 \mathrm{~mm}$ glycine, and 0.1\% SDS; at 80 constant volts for $2 \mathrm{~h}$ ). Separated proteins were then electrotransferred onto polyvinylidene difluoride membranes (Bio-Rad Laboratories, Hercules, CA) using Tris-glycine buffer, pH 8.4 (containing 25 mm Tris, 192 mu glycine, and $10 \%$ methanol). To probe any specific protein, membranes were pretreated with Tris-buffered saline, $5 \%$ nonfat dry milk, and $0.05 \%$ Tween 20 (TBST) solution. Binding of antibodies was also done under the same conditions. To detect the levels of different PKA subunits, anti-human $\mathrm{PKA}_{\mathrm{C} \alpha}$ (clone 5B; 1:1500 dilution; BD Biosciences, San Jose, $\mathrm{CA}$ ), anti-mouse $\mathrm{PKA}_{\mathrm{RI}}$ (clone 18; 1:500 dilution; $\mathrm{BD}$ Biosciences), anti-human $\mathrm{PKA}_{\mathrm{RII} \alpha}$ (clone 40; 1:1500 dilution; BD Biosciences), anti-human $\mathrm{PKA}_{\mathrm{RII} \beta}$ (clone $45 ; 1: 1500$ dilution; BD Biosciences), and anti-actin (clone AC-40; 1:1500 dilution; Sigma) monoclonal primary antibodies were used. In this study, a ubiquitous protein, actin, was measured as a methodological control to ensure uniformity in our Western blot procedure. All of these primary antibody-binding reactions were done in a shaker at room temperature for $2 \mathrm{~h}$. At the completion of primary antibody reactions, blots were washed in the TBST solution containing no dry milk (typically three washes, each for $5 \mathrm{~min}$ ). After the final wash, blots were treated with secondary antibody [antimouse IgG (heavy plus light) HRP conjugate at 1:10,000 dilution; Promega, Madison, WI] diluted with the TBST buffer. After the secondary antibody reactions, blots were again washed in TBST solution containing no dry milk (three washes, each for $5 \mathrm{~min}$ ). The resulting immunocomplexes were detected with a chemiluminescent substrate (SuperSignal West Femto; Pierce Biotechnology, Rockford, IL). The quantification of the immunoreactive band was performed using a Kodak imaging densitometer (PerkinElmer, Shelton, CT). Each sample was probed at least three times. The net intensities were equalized according to exposure time. For the quantification of $\mathrm{PKA}_{\mathrm{C} \alpha}, \mathrm{PKA}_{\mathrm{RI}}, \mathrm{PKA}_{\mathrm{RII} \alpha}, \mathrm{PKA}_{\mathrm{RII} \beta}$, and actin levels in the PPT, mPRF, mPFC, and AHTh, chemiluminescent values obtained from the control REM sleep group of rats were normalized. The averaged means of these normalized values were considered to be the $100 \%$ value. Finally, in the high and low REM sleep groups of animals, the chemiluminescent value in each band was calculated as a percentage level compared with the comparable normalized mean chemiluminescent value in the control REM sleep group. These percentage level values were then used for the statistical analysis.

Tissue collection and estimation of PKA activity. The tissue collection procedure for the PKA activity in the PPT and MPRF is identical to the tissue collection procedure described above for the PKA subunit expression analysis. To estimate PKA activity, the frozen tissue $(0.1-0.2 \mathrm{~g})$ isolated from the brain was initially homogenized (Sonic Dismembrator; Fisher Scientific) in $500 \mu \mathrm{l}$ of ice-cold cell lysis buffer (mammalian CelLytic reagent; Sigma). The homogenate was then centrifuged at 14,000 $\mathrm{rpm}$ for $15 \mathrm{~min}$ at $4^{\circ} \mathrm{C}$ to remove cell debris. The supernatant was saved as crude extract. For the activity assay, the crude extract was further purified by passing it through a mini spin column (Micro Bio-Spin 6 chromatographic column; Bio-Rad Laboratories); however, before loading the ex- tract, the column was prepared and equilibrated. Excess of the suspension solution present with the matrix was removed, and $250 \mu$ l of cell lysis buffer was added to equilibrate it. Any remaining amount of liquid that remained in the column bed after equilibration was also removed by spinning the column at $5000 \mathrm{rpm}$ for $30 \mathrm{~s}$ at $4^{\circ} \mathrm{C}$. The $200 \mu \mathrm{l}$ of crude extract was then loaded on the equilibrated column and spun at 5000 rpm for $2 \mathrm{~min}$ at $4^{\circ} \mathrm{C}$. Afterward, the flow-through solution was collected and saved as cleared extract. To prevent any loss of enzymatic activity in the preparation, a glycerol solution was added to the cleared extract, creating a final concentration of $10 \%$. An aliquot of this glycerol-mixed cleared extract was used to measure the protein concentration [by Bradford's method (Bradford, 1976)]. The rest was saved at $-20^{\circ} \mathrm{C}$ until additional use.

In our study, PKA activity was measured using a nonradioactive assay method, the PepTag assay system that was developed by Promega (White and Shultz, 1992; Sahir et al., 2001; Goueli et al., 2004). The required assay kit was obtained from Promega. For the activity assay, empty $1.5 \mathrm{ml}$ Eppendorf tubes (Eppendorf Scientific, Westbury, NY) were placed on ice and appropriately labeled (one for each experimental sample, one for the positive control, and another for the negative control). Once chilled, a $5 \mu \mathrm{l}$ volume of PKA buffer (containing $100 \mathrm{~mm}$ Tris- $\mathrm{HCl}, \mathrm{pH}$ 7.4, 50 $\mathrm{mM} \mathrm{MgCl}_{2}$, and $5 \mathrm{~mm} \mathrm{ATP}$ ) was poured into each tube, followed by a $5 \mu \mathrm{l}$ volume of PKA substrate (containing $2 \mu \mathrm{g}$ of colored PepTag A1 Kemptide protein). Next, $1 \mu \mathrm{l}$ of company-supplied protector solution was added to each tube containing PKA buffer and substrate. At this point, a $10 \mu \mathrm{l}$ volume of brain extract (containing $2 \mu \mathrm{g}$ of total protein) was added only to tubes labeled with both experimental condition and anatomical site. No brain extract was added to either the positive or negative control tube. Instead, $10 \mu \mathrm{l}$ of company-supplied standard enzyme [containing $20 \mathrm{ng}$ of purified form of the PKA catalytic (C) subunit] was added to the positive control tube, and $10 \mu$ of ice-cold deionized water was added to the negative control tube. After adding all of the required reagents and the appropriate enzyme, the final volume of each tube was adjusted to a total volume of $25 \mu \mathrm{l}$ by adding $4 \mu \mathrm{l}$ of ice-cold deionized water. The reaction mixes were then incubated at room temperature for $60 \mathrm{~min}$. After incubation, the tubes were placed in a $95^{\circ} \mathrm{C}$ water bath for $10 \mathrm{~min}$ to stop the reaction. The samples were then quickly spun in a microfuge to pull down the condensate and ultimately loaded in a $1 \%$ agarose gel. The gel used for the study was prepared in $50 \mathrm{~mm}$ Tris- $\mathrm{HCl}$ buffer, $\mathrm{pH}$ 8.0, and was electrophoresed in the same solution. Electrophoresis continued for 20-30 min at 100 constant volts. After electrophoresis, the gel was photographed under UV light using a Kodak Image Station (440CF; Eastman Kodak, Rochester, NY). For quantitation of the bands, which represented both the phosphorylated and nonphosphorylated Kemptides, the image intensities were converted to OD by using the Kodak image analysis software.

Experimental design to measure the PKA subunit expression and activity at three different levels of REM sleep. On the day after the last adaptation recording session, when day-to-day variation on the total amount of REM sleep stabilized, rats underwent a session of baseline sleep-wakefulness recordings (between 9:00 A.M. and 2:00 P.M.). The following day, experimental recording sessions began. During the experimental recording session, each animal was connected to the polygraphic recording system at 8:55 A.M. In the next room, polygraphic signs of the sleepwake cycle were continuously observed on a computer monitor (between 9:00 A.M. and 2:00 P.M.). At this point, the 18 rats were randomly divided into three groups. The experimental design of these studies is summarized in Figure $1 A$. Group $1(n=6$ rats) rats were recorded for $5 \mathrm{~h}$ (between 9:00 A.M. and 2:00 P.M.) of undisturbed sleep-wakefulness [hereafter, group 1 is labeled as "baseline/control REM sleep" ("BR")]. The experimental protocol for group 2 ( $n=6$ rats) animals was almost identical to the protocol described above for the BR group, except that for group 2 animals, from 11:00 A.M. to 2:00 P.M., REM sleep episodes were selectively terminated at the beginning (within 3-5 s) of each episode while the animals were connected to the polygraphic recording system [hereafter, group 2 is labeled as "REM sleep deprived" ("RD")]. In group 3 ( $n=6$ rats) animals, REM sleep episodes were selectively terminated between 9:00 A.M. and 12:00 P.M., after which they were allowed to have undisturbed sleep-wake [hereafter, group 3 is labeled as "REM sleep 


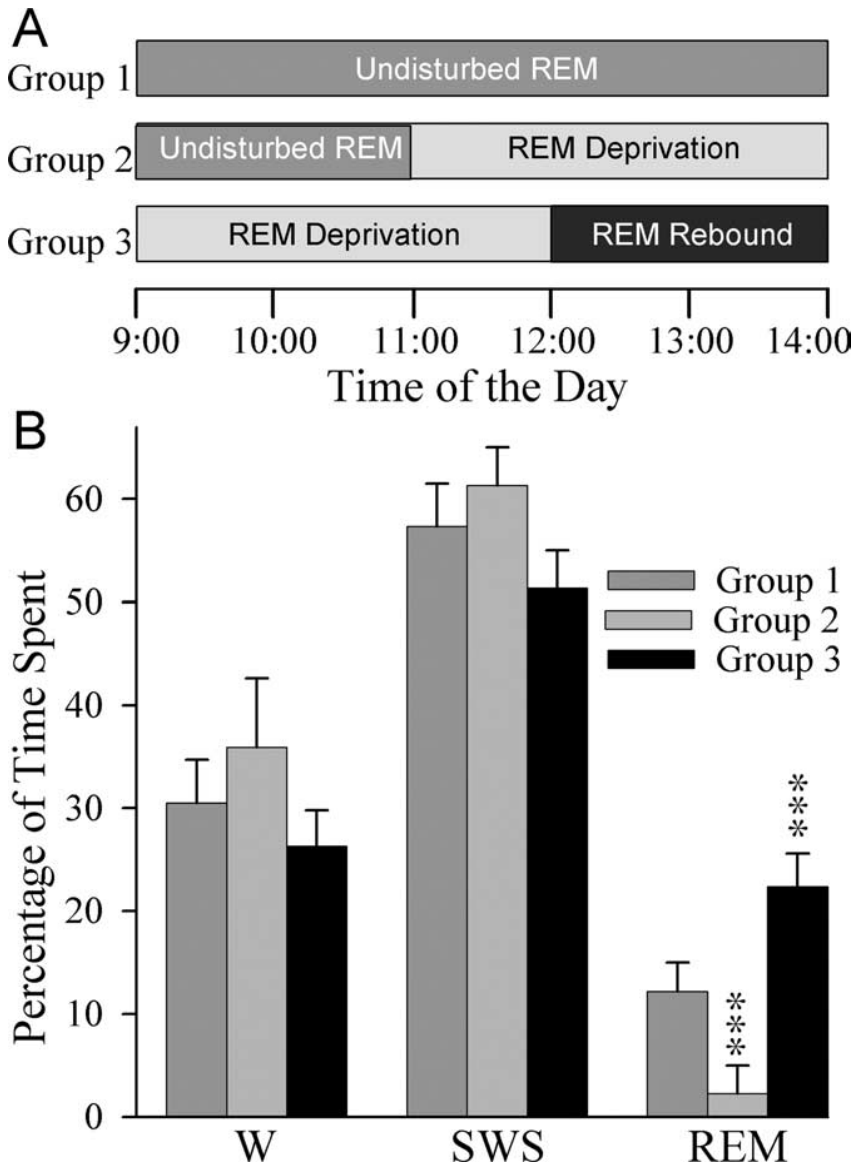

Figure 1. Experimental designs for low and high REM sleep conditions. $\boldsymbol{A}, \mathrm{G}$ roup 1 rats were allowed to have a $5 \mathrm{~h}$ period (between 9:00 A.M. and 2:00 P.M.) of undisturbed sleep-wake $(S-W)$ cycle with REM sleep. Group 2 rats were allowed to have undisturbed S-W cycle with REM sleep between 9:00 and 11:00 A.M., after which REM sleep episodes were selectively terminated between 11:00 A.M. and 2:00 P.M. REM sleep episodes in group 3 rats were selectively terminated from the ongoing $S-W$ cycle between 9:00 A.M. and 12:00 P.M., followed by undisturbed S-W with REM sleep between 12:00 P.M. and 2:00 P.M. B, Histograms showing the total percentages of time (mean \pm SD) spent in W, SWS, and REM sleep during the last $2 \mathrm{~h}$ (between 12:00 and 2:00 P.M.) of S-W data. Note that compared with group 1, group 2 rats had $77 \%$ less and group 3 rats had $84 \%$ more REM sleep during the last $2 \mathrm{~h}$ of $\mathrm{S}-\mathrm{W}$ recordings. Therefore, in this study, group 1 rats were categorized as having a normal amount of REM sleep, whereas group 2 and group 3 rats were categorized as having low REM sleep and high REM sleep, respectively. Post hoc Scheffé's F test (compared with group 1), ${ }^{* * *} p<0.001$.

rebound" ("RR")]. In summary, the main difference between these three groups of animals is the amount of REM sleep during the last $2 \mathrm{~h}$ (between 12:00 A.M. and 2:00 P.M.). The BR group had a normal amount of REM sleep. The RD group had $\sim 77 \%$ less REM sleep than the BR group. The RR group had $84 \%$ more REM sleep than the BR group (Fig. $1 B$ ). At 2:02 P.M., all rats were killed with $\mathrm{CO}_{2}$ to collect brain tissues for the Western blotting as described above.

In addition to these 18 rats, three other rats were subjected to similar experimental design to study PKA activity in the PPT and mPRF at three different REM sleep conditions. Of those three rats, one rat was subjected to the BR protocol, and this rat had $11.5 \%$ REM sleep. The second rat was subjected to RD protocol, and this rat had only $2 \%$ REM sleep. The third rat was subjected to RR protocol and had 20.1\% REM sleep. At 2:02 P.M., these three rats were killed with $\mathrm{CO}_{2}$ to collect brain tissues for estimating PKA activity in the PPT and MPRF as described above.

Experimental design to study the effects of Rp-cAMPS microinjection on the sleep-wake cycle. After the adaptation recording sessions, microinjection sessions began. During experimental sessions, animals ( $n=35$ rats) were connected to the polygraphic recording system 15 min before a microinjection into the PPT. The microinjection system consisted of a 32 gauge stainless steel injector cannula with a 26 gauge collar that extended $2.0 \mathrm{~mm}$ beyond the implanted guide tube. The collar was connected to a $1.0 \mu \mathrm{l}$ motor-driven Hamilton microsyringe with PE 20 tubing. While the animal was connected to the recording system, the stylet was removed, and an injector with either control vehicle (100 nl volume of $0.9 \%$ saline $)$ or one of four doses of Rp-cAMPS $(0.28,0.55,1.1$, and 2.2 $\mathrm{nmol} / 100 \mathrm{nl}$ ) was introduced through the guide tube for the injection. One minute after the insertion of the injector cannula, $100 \mathrm{nl}$ of control saline or one of the four doses of Rp-cAMPS was microinjected over a $60 \mathrm{~s}$ period (Pump II Pico Plus; Harvard Apparatus, Holliston, MA). The injector cannula was gently withdrawn 2 min after the injection, and the stylet was reinserted into the guide tube. During the microinjection, animals were free to move around the cage with the cannula in place. Immediately after completion of the microinjection procedure, polygraphic variables were recorded continuously for $6 \mathrm{~h}$ (between 10:00 A.M. and 4:00 P.M.), when rats would normally be sleeping (Datta, 2000). Each of these rats received a single microinjection in either the right or the left PPT in a single experimental recording session. None of the rats was used for more than one microinjection recording session. At the end of all experimental sessions and before perfusion, $100 \mathrm{nl}$ of black ink was microinjected $1 \mathrm{~mm}$ dorsal to the injection site for localizing the injection site as described previously (Datta, 2002; Datta et al., 2002).

Histological localization of injection site. At the conclusion of the microinjection experiments, rats were deeply reanesthetized with pentobarbital $(60 \mathrm{mg} / \mathrm{kg}$, i.p.) and perfused transcardially with heparinized cold phosphate buffer $(0.1 \mathrm{M}, \mathrm{pH} 7.4)$ followed by $4 \%$ paraformaldehyde in $0.1 \mathrm{M}$ phosphate buffer. The brains were removed and processed for $\mathrm{NADPH}$-diaphorase staining and histological localization of injection sites as described previously (Datta et al., 2002; Datta and Prutzman, 2005). This NADPH-diaphorase staining was performed to identify the cholinergic cell compartment of the PPT. Histological identification showed that in all 35 rats, unilateral microinjections were placed within the cholinergic cell compartment of the PPT (Fig. 2).

Data analysis of expression of PKA subunits and effect of Rp-cAMPS on variation in sleep-wake cycle. To determine the effects of REM sleep manipulations on changes in the sleep-wake data and expression of PKA subunits, the polygraphic measures of the rats $(n=18)$ were analyzed to calculate the total percentages of time spent in W, SWS, and REM sleep in two different recording sessions: during the last adaptation recording session (between 9:00 A.M. and 2:00 P.M.) and during the last $2 \mathrm{~h}$ of the experimental recording session (between 12:00 P.M. and 2:00 P.M.), before they were killed to collect brain tissues. These sleep-wake data were subjected to one-factor ANOVAs and post hoc Scheffé's $F$ tests to compare the total percentages of time spent in W, SWS, and REM sleep among the BR, RD, and RR groups (StatView statistical software; Abacus Concepts, Berkeley, CA). For the PKA subunit data, one-factor ANOVAs and post hoc Tukey's tests were used to compare the levels of $\mathrm{PKA}_{\mathrm{C} \alpha}$, $\mathrm{PKA}_{\mathrm{RI}}, \mathrm{PKA}_{\mathrm{RII} \alpha}, \mathrm{PKA}_{\mathrm{RII} \beta}$, and actin in the PPT, mPRF, mPFC, and AHTh among BR, RD, and RR groups using SigmaStat statistical software (Systat Software, Point Richmond, CA).

For the purpose of determining possible effects of Rp-cAMPS on sleep and wakefulness, the polygraphic measures provided the following dependent variables, which were quantified for each recording session: (1) percentage of recording time spent in W, SWS, and REM sleep; (2) latency to onset of the first episode of REM sleep after the onset of recordings; (3) total number of REM sleep episodes; and (4) mean duration of REM sleep episodes. The effects of the five different treatments [(1) control saline, (2) $0.28 \mathrm{nmol}$ of Rp-cAMPS, (3) $0.55 \mathrm{nmol}$ of Rp-cAMPS, (4) $1.1 \mathrm{nmol}$ of Rp-cAMPS, and (5) $2.2 \mathrm{nmol}$ of Rp-cAMPS] on the percentages of W, SWS, and REM sleep were statistically analyzed using a two-way ANOVA with time as a repeated-measure variable (six levels corresponding to six $1 \mathrm{~h}$ epochs after injections) and treatment as a between-subjects variable (five levels corresponding to the five different treatments). After a two-way ANOVA, post hoc Scheffé's $F$ tests were done to determine the individual levels of significant difference between the control (saline) and the four different doses of Rp-cAMPS treatment protocols at six individual data points. The latency, number, and duration of REM sleep episodes were analyzed using a one-way ANOVA followed by post hoc Scheffés $F$ tests. Statistical analyses (two-way 




Figure 2. Anatomical location of analyzed microinjection sites. Schematic coronal sections through the brainstem are illustrated at levels 1.70, 1.20, 1.00, and $0.70 \mathrm{~mm}$ anterior (labeled at the top right of each section). Open circles $(n=7)$ indicate the location of control saline, and filled circles $(n=28)$ indicate the location of Rp-cAMPS injector tips. 4, Trochlear nucleus; Aq, aqueduct; $\mathrm{ATg}$, anterior tegmental nucleus; $\mathrm{BIC}$, nucleus brachium inferior colliculus; $\mathrm{CG}$, central gray; $\mathrm{CnF}$, cuneiform nucleus; ctg, central tegmental tract; DR, dorsal raphe nucleus; $\mathrm{dtg}$, dorsal tegmental bundle; IC, inferior colliculus; InCo, intercollicular nucleus; LL, lateral lemniscus; Me5, mesencephalic trigeminal tract/nucleus; MiTg, microcellular tegmental nucleus; mlf, medial longitudinal fasciculus; Pa4, paratrochlear nucleus; PMR, paramedian raphe; Pn0, pontine reticular nucleus, oral; RR, retrorubral nucleus; rs, rubrospinal tract; scp, superior cerebellar peduncle; SPTg, subpeduncular tegmental nucleus; ts, tectospinal tract; VTg, ventral tegmental nucleus; xscp, decussation of superior cerebellar peduncle. Scale bar, $600 \mu \mathrm{m}$.

ANOVA, one-way ANOVA, and Scheffé's $F$ test) were performed using StatView statistical software (Abacus Concepts).

\section{Results}

\section{Effects of selective REM sleep deprivation protocol on wake-sleep states}

Selective REM sleep deprivation protocols are illustrated in Figure $1 A$. The total percentages of time spent in W, SWS, and REM sleep during the $5 \mathrm{~h}$ baseline recording session (between 9:00 A.M. and 2:00 P.M.) were not significantly different (one-factor ANOVA) among the BR (group 1), RD (group 2), and RR (group 3 ) groups of animals. Also, during the last $2 \mathrm{~h}$ (between 12:00 P.M. and 2:00 P.M.) of the same baseline recording session, the total percentages of time spent in REM sleep were not significantly different (one-factor ANOVA) among the BR (11.5 \pm $2.1 \%$, mean $\pm \mathrm{SD}), \mathrm{RD}(13.1 \pm 1.8 \%)$, and $\mathrm{RR}(12.4 \pm 1.6 \%)$ groups. Thus, in the baseline recording conditions, the groups were initially equal in terms of time spent in W, SWS, and REM sleep. One-factor ANOVA also revealed that the total percentages of REM sleep during the last $2 \mathrm{~h}$ were not significantly different among experimental recording sessions of BR $(12.2 \pm 2.8 \%)$ and baseline recording sessions of $\mathrm{BR}, \mathrm{RD}$, and $\mathrm{RR}$ groups. These results suggest that during the experimental recording session, the BR group of rats spent a normal amount of time in REM sleep. Because the BR group of rats had a normal amount of REM sleep during the experimental recording session, this group of animals was used as our control. To determine the effects of selective REM sleep deprivation, sleep-wake data collected during the last $2 \mathrm{~h}$ of experimental recording sessions were compared among $\mathrm{BR}, \mathrm{RD}$, and RR groups. One-factor ANOVAs revealed a significant group difference in the total percentage of time spent in REM sleep $\left(F_{(2,15)}=80.56 ; p<0.001\right)$ but not in $\operatorname{SWS}\left(F_{(2,15)}=1.9 ; p=\right.$ $0.17)$ and $\mathrm{W}\left(F_{(2,15)}=2.43 ; p=0.11\right)$. Post hoc Scheffé's $\mathrm{F}$ tests show that compared with the BR group, the RD group had a significantly lower percentage of REM sleep (77.05\% lower than normal; $p<0.001$ ) (Fig. $1 B$ ). Thus, hereafter, the RD group is also labeled as the "low REM sleep" group. Similar post hoc tests between the BR and RR groups show that the RR group of rats had a significantly higher percentage of REM sleep (83.6\% more than normal; $p<0.001$ ) (Fig. $1 B$ ). Thus, hereafter, the RR group is also labeled as the "high REM sleep" group.

\section{Distribution of PKA subunits in the PPT and MPRF at low and high REM sleep conditions}

For the induction as well as maintenance of REM sleep, PPT and mPRF have been identified as the two most important regions in the brainstem (Datta, 1995; Pace-Schott and Hobson, 2002). In this study, for the first time, we are looking at the distribution of different subunits of PKA in these two REM sleep-regulating regions. We have measured the levels of $\mathrm{PKA}_{\mathrm{C} \alpha}, \mathrm{PKA}_{\mathrm{RI}}, \mathrm{PKA}_{\mathrm{RII} \alpha}$, $\mathrm{PKA}_{\mathrm{RII} \beta}$, and actin protein expressions in the PPT and $\mathrm{mPRF}$ in three different REM sleep conditions: (1) after $2 \mathrm{~h}$ of a normal amount of REM sleep (normal REM sleep group), (2) after $2 \mathrm{~h}$ of a very low amount of REM sleep (low REM sleep group), and (3) after $2 \mathrm{~h}$ of a very high amount of REM sleep (high REM sleep group). The changes in the expression of different subunits of PKA and actin protein levels in the PPT and MPRF at these three REM sleep conditions are illustrated in Figure 3. One-factor ANOVAs between three conditions (normal, low, and high amounts of REM sleep) revealed significant differences in the PPT levels of $\mathrm{PKA}_{\mathrm{C} \alpha}\left(F_{(2,15)}=1021.36 ; p<0.001\right), \mathrm{PKA}_{\mathrm{RI}}$ $\left(F_{(2,15)}=36.64 ; p<0.001\right)$, and $\mathrm{PKA}_{\mathrm{RII} \beta}\left(F_{(2,15)}=218.65 ; p<\right.$ $0.001)$ but not in the $\mathrm{PKA}_{\mathrm{RII} \alpha}\left(F_{(2,15)}=0.37 ; p=0.40\right)$ and actin $\left(F_{(2,15)}=0.80 ; p=0.47\right)$. These results indicated that in three different REM sleep conditions, the PPT levels of $\mathrm{PKA}_{\mathrm{C} \alpha}, \mathrm{PKA}_{\mathrm{RI}}$, and $\mathrm{PKA}_{\mathrm{RII} \beta}$ subunits are significantly different but the levels of $\mathrm{PKA}_{\mathrm{RII} \alpha}$ subunit and actin protein are comparable. In an effort to determine the specific effects of variable REM sleep conditions on the levels of these proteins in the PPT, the measured concentrations of these proteins in the PPT in the low and high REM sleep groups were compared separately with the normal REM sleep group ( post hoc Tukey's tests). These computations revealed that the low REM sleep group PPT levels of PKA $\mathrm{C}_{\alpha}$ (32.9\% lower; $q=$ 48.93; $p<0.001), \mathrm{PKA}_{\mathrm{RI}}(10.85 \%$ lower; $q=6.98 ; p<0.01)$, and $\mathrm{PKA}_{\mathrm{RII} \beta}(22.19 \%$ lower; $q=28.98 ; p<0.001)$ subunits are significantly lower (Fig. $3 B$ ). These results suggest that a reduction of the percentage of time spent in REM sleep (77.05\% decrease) decreases the levels of $\mathrm{PKA}_{\mathrm{C} \alpha}, \mathrm{PKA}_{\mathrm{RI}}$, and $\mathrm{PKA}_{\mathrm{RII} \beta}$ subunit expression in the PPT (Fig. $3 B$ ). Similar comparisons (Tukey's tests) demonstrated that the high REM sleep group PPT levels of $\mathrm{PKA}_{\mathrm{C} \alpha}$ subunit are significantly higher (7.51\% higher; $q=11.16$; $p<0.01)$, but the PKA $_{\mathrm{RI}}(18.73 \%$ lower; $q=12.10 ; p<0.001)$ and $\mathrm{PKA}_{\mathrm{RII} \beta}(7.20 \%$ lower; $q=9.40 ; p<0.01)$ subunits are significantly lower (Fig. $3 B$ ). These results suggest that, in the PPT, with increased percentage of time spent in REM sleep (83.6\% increase), the level of $\mathrm{PKA}_{\mathrm{C} \alpha}$ subunit expression increases and, at the same time, the levels of $\mathrm{PKA}_{\mathrm{RI}}$ and $\mathrm{PKA}_{\mathrm{RI} \beta}$ subunit expression decrease.

The results of this study also demonstrated that at these three different REM sleep conditions, the mPRF levels of $\mathrm{PKA}_{\mathrm{C} \alpha}\left(F_{(2,15)}=\right.$ $119.99 ; p<0.001), \mathrm{PKA}_{\mathrm{RII} \alpha}\left(F_{(2,15)}=6.0 ; p<0.01\right)$, and $\mathrm{PKA}_{\mathrm{RII} \beta}$ 


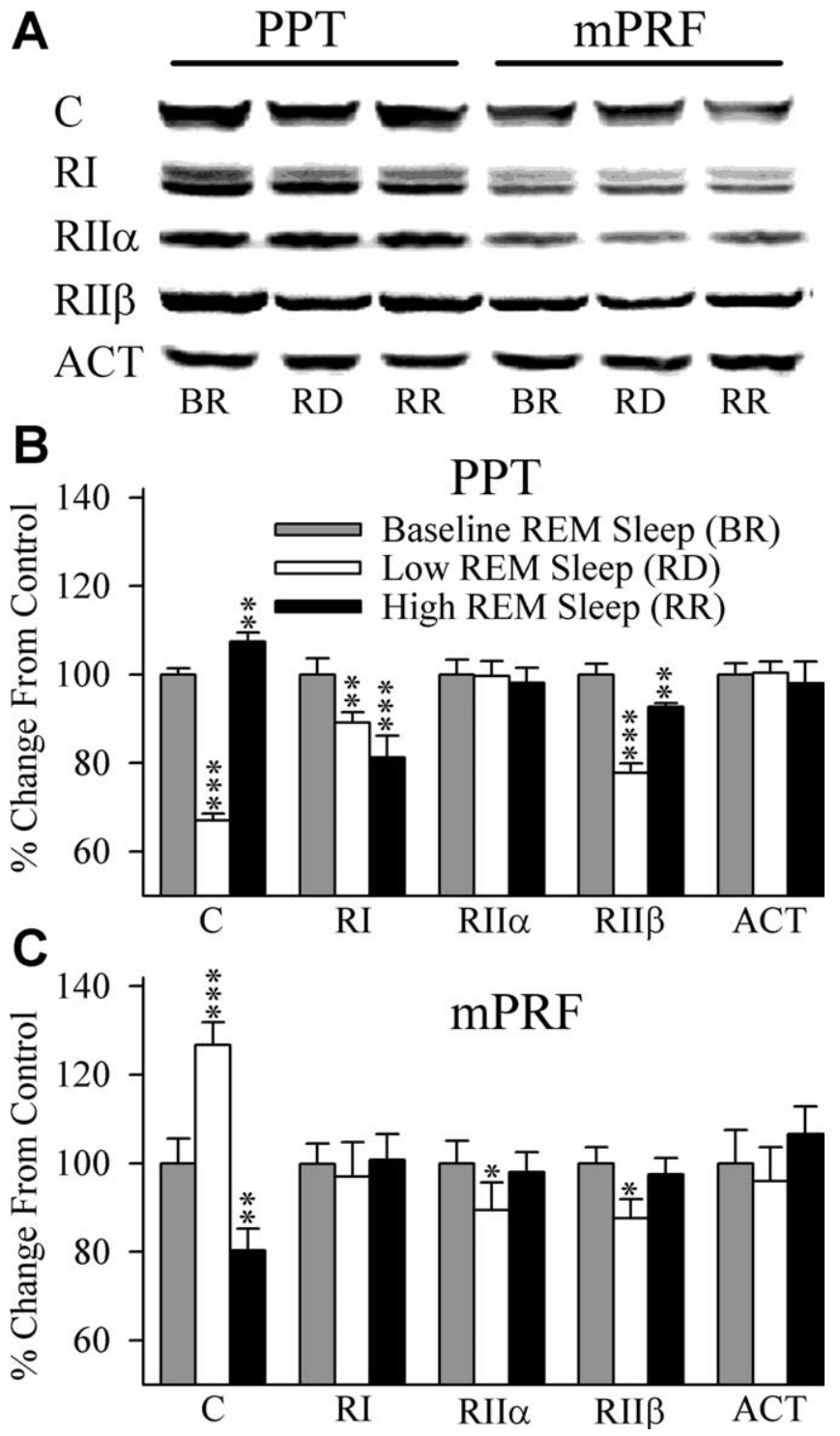

Figure 3. Effects of high and low REM sleep on the levels of PKA subunit expression in the PPT and mPRF. $A$, Western blots of $C, R I$, RIl $\alpha$, and RII $\beta$ subunits of PKA and actin (ACT) in the PPT and mPRF during three conditions: BR, RD, and RR. $B$, Data from densitometric analysis of Western blots of PPT are expressed as a percentage of control. Each bar represents mean \pm SD of the BR (gray bars), RD (white bars), or RR (black bars) group of animals ( $n=6$ rats per group). C, Data from densitometric analysis of Western blots of $\mathrm{mPRF}$ are expressed as a percentage of control. Note that PPT levels of C decreased during low REM sleep and increased during high REM sleep, whereas PPT levels of RI and RII $\beta$ decreased in both sleep conditions. In the mPRF, low REM sleep increased levels of C and decreased levels of RII $\alpha$ and RII $\beta$. Conversely, high REM sleep decreased levels of $C$ in the mPRF. Also, note that levels of ACT in the PPT and mPRF remained unchanged in both sleep conditions. Post hoc Tukey's test (compared with control REM), ${ }^{*} p<0.05 ;{ }^{* *} p<0.01 ;{ }^{* * *} p<0.001$.

$\left(F_{(2,15)}=30.71 ; p<0.001\right)$ subunit expression are different, whereas the levels of $\mathrm{PKA}_{\mathrm{RI}}\left(F_{(2,15)}=0.59 ; p=0.56\right)$ subunit and actin protein $\left(F_{(2,15)}=3.40 ; p=0.06\right)$ are comparable. Individual post hoc tests (Tukey's tests) revealed that in the low REM sleep group, the level of $\mathrm{PKA}_{\mathrm{C} \alpha}$ subunit expression in the mPRF is significantly higher (26.73\% higher; $q=12.59$; $p<0.001)$, but the levels of $\mathrm{PKA}_{\mathrm{RII} \alpha}(10.59 \%$ lower; $q=7.13 ; p<0.05)$ and $\mathrm{PKA}_{\mathrm{RII} \beta}(12.36 \%$ lower; $q=8.05 ; p<0.05)$ subunit expression are significantly lower (Fig. $3 C$ ). These results indicated that the decreased percentage of time spent in REM sleep increased the level of the PKA $\mathrm{C}_{\alpha}$ subunit expression while simultaneously de- creasing levels of $\mathrm{PKA}_{\mathrm{RII} \alpha}$ and $\mathrm{PKA}_{\mathrm{RII} \beta}$ expression in the mPRF. Similar post hoc tests revealed that in the high REM sleep group, the level of $\mathrm{PKA}_{\mathrm{C} \alpha}$ subunit expression is significantly lower (19.61\% lower; $q=9.23 ; p<0.01)$ in the mPRF. This result reveals that with increased percentage of time spent in REM sleep, the level of $\mathrm{PKA}_{\mathrm{C} \alpha}$ subunit expression decreases in the mPRF.

\section{Effects of REM sleep changes on the AHTh and mPFC levels} of PKA subunits

Having documented the REM sleep-related changes in levels of PKA subunit expression in the PPT and MPRF, we further analyzed these PKA subunits in two other regions of the brain: (1) in the AHTh, known to be involved in the regulation of SWS (PaceSchott and Hobson, 2002), and (2) in the mPFC, known to be involved in cognitive functions but not in sleep-wake activity (Goldman-Rakic, 1987; Dalley et al., 2004). The changes in the levels of different PKA subunits and actin protein in the AHTh and $\mathrm{mPFC}$ at three different REM sleep conditions are illustrated in Figure 4. One-factor ANOVAs demonstrated that, at three different REM sleep conditions, the AHTh levels of $\mathrm{PKA}_{\mathrm{RI}}\left(F_{(2,15)}=\right.$ 171.03; $p<0.001)$ and $\mathrm{PKA}_{\mathrm{RII} \beta}\left(F_{(2,15)}=205.17 ; p<0.001\right)$ subunit expression are significantly different, but the levels of $\mathrm{PKA}_{\mathrm{C} \alpha}\left(F_{(2,15)}=0.84 ; p=0.45\right)$ and $\mathrm{PKA}_{\mathrm{RII} \alpha}\left(F_{(2,15)}=0.54 ; p=\right.$ $0.38)$ subunits and actin $\left(F_{(2,15)}=0.79 ; p=0.47\right)$ protein are comparable. Individual post hoc tests (Tukey's tests) of the low REM sleep group revealed that in the AHTh, levels of PKA (47.86\% higher; $q=16.97 ; p<0.001)$ and $\mathrm{PKA}_{\mathrm{RII} \beta}(52.73 \%$ higher; $q=19.64 ; p<0.001)$ subunit expressions are significantly higher (Fig. 4C). Similar post hoc tests of the high REM sleep group revealed that in the AHTh, levels of $\mathrm{PKA}_{\mathrm{RI}}(72.54 \%$ higher; $q=25.72 ; p<0.001)$ and $\mathrm{PKA}_{\mathrm{RII} \beta}(74.86 \%$ higher; $q=$ 27.88; $p<0.001$ ) subunit expression are significantly higher (Fig. $4 C)$. These results indicated that in the AHTh, the levels of $P K A_{\mathrm{RI}}$ and $\mathrm{PKA}_{\mathrm{RII} \beta}$ subunit expression increase with both high and low REM sleep conditions.

One-factor ANOVAs between the normal, low, and high REM sleep conditions revealed significant differences in the $\mathrm{MPFC}$ levels of $\mathrm{PKA}_{\mathrm{C} \alpha}\left(F_{(2,15)}=37.12 ; p<0.001\right)$ and $\mathrm{PKA}_{\mathrm{RI}}\left(F_{(2,15)}=\right.$ $31.54 ; p<0.001)$ subunits but not in the levels of $\operatorname{PKA}_{\mathrm{RII} \alpha}\left(F_{(2,15)}=\right.$ $0.83 ; p=0.49)$ and $\mathrm{PKA}_{\mathrm{RII} \beta}\left(F_{(2,15)}=0.64 ; p=0.42\right)$ subunits and actin $\left(F_{(2,15)}=0.81 ; p=0.46\right)$ protein. In the $\mathrm{mPFC}$, individual post hoc tests (Tukey's tests) revealed that in the low REM sleep condition, the level of $\mathrm{PKA}_{\mathrm{RI}}(11.66 \%$ higher; $q=10.93$; $p<0.01$ ) subunit is significantly higher but the level of $\mathrm{PKA}_{\mathrm{C} \alpha}$ (9.71\% lower; $q=5.72 ; p<0.01)$ subunit is significantly lower (Fig. $4 B$ ). Similar post hoc tests between normal and high REM sleep conditions revealed that in the $\mathrm{MPFC}$, the high REM sleep condition level of the $\mathrm{PKA}_{\mathrm{RI}}$ (16.57\% higher; $q=10.93$; $p<$ 0.001 ) subunit is significantly higher and the level of the PKA $\alpha \alpha$ (20.68\% lower; $q=12.18 ; p<0.001)$ subunit is significantly lower (Fig. $4 B$ ). These results suggest that in the $\mathrm{MPFC}$, in both high and low REM sleep, the level of the $\mathrm{PKA}_{\mathrm{C} \alpha}$ subunit decreases and the level of $\mathrm{PKA}_{\mathrm{RI}}$ increases.

\section{Effects of REM sleep changes on the PPT and mPRF PKA activity}

Because increased $\mathrm{PKA}_{\mathrm{C} \alpha}$ expression is a positive indication of increased PKA activity, and we have documented REM sleepspecific alteration of $\mathrm{PKA}_{\mathrm{C} \alpha}$ expression in the PPT and $\mathrm{mPRF}$, we expected to see similar REM sleep-specific alteration of PKA activity in the PPT and mPRF. The PKA activity in the PPT and $\mathrm{mPRF}$ at three different levels of REM sleep are illustrated in Figure 5. In these three different REM sleep conditions, the per- 


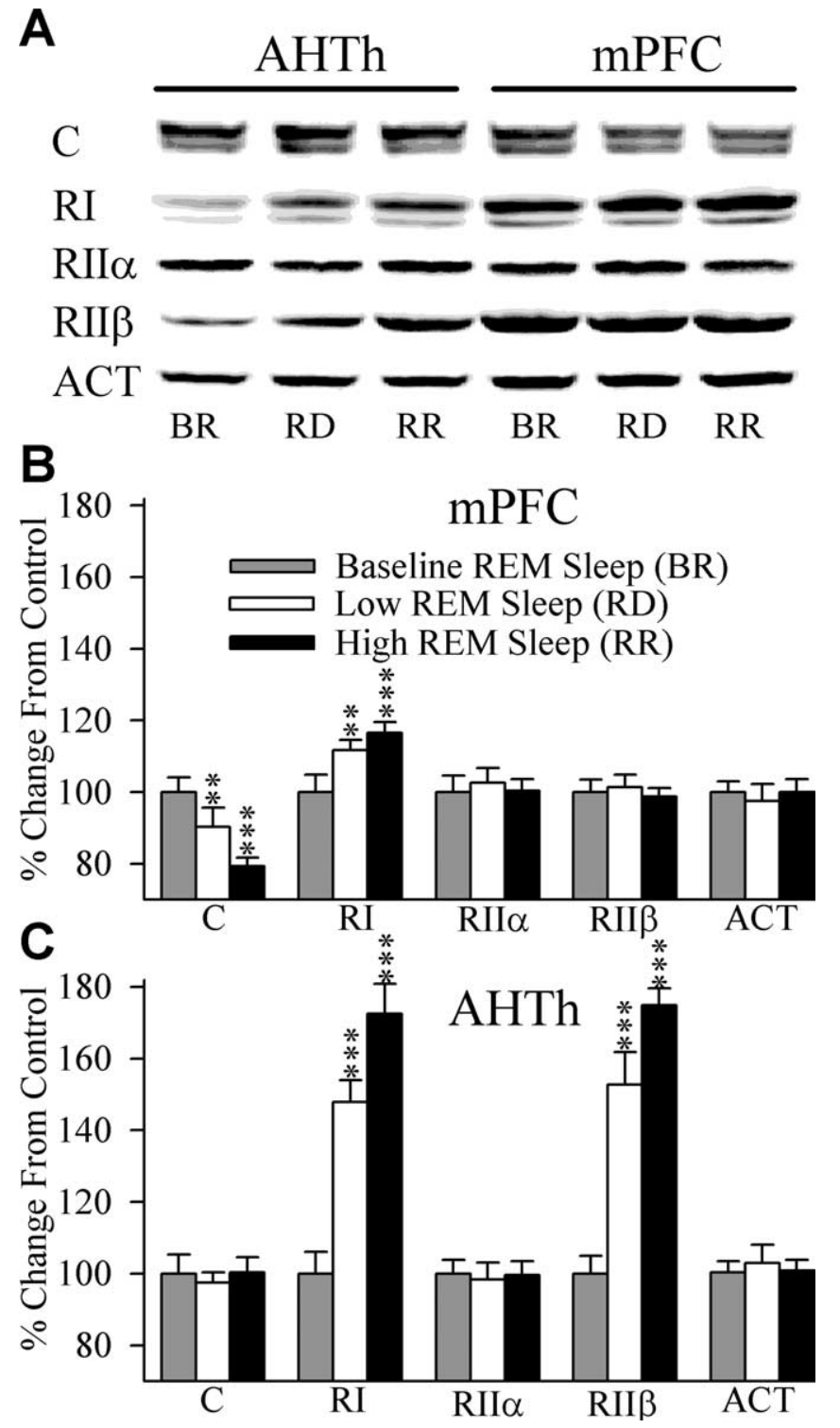

Figure 4. Effects of high and low REM sleep on levels of expression of different PKA subunits in the AHTh and mPFC. $A$, Western blots of $C, \mathrm{Rl}, \mathrm{Rll} \alpha$, and Rll $\beta$ subunits of PKA and actin (ACT) in the AHTh and $\mathrm{mPFC}$ during three conditions: BR, RD, and RR. $\boldsymbol{B}$, Data from densitometric analysis of Western blots of $\mathrm{mPFC}$ are expressed as a percentage of control. Each bar represents mean $\pm S D$ of the BR (gray bars), RD (white bars), or RR (black bars) group of animals ( $n=6$ rats per group). C, Data from densitometric analysis of Western blots of AHTh are expressed as a percentage of control. Note that during both low and high REM sleep, the MPFC levels of $C$ decreased and RI increased. In the AHTh, the levels of RI and RII $\beta$ increased during both low and high REM sleep. ACT levels in the mPFC and AHTh remained unchanged in both sleep conditions. Post hoc Tukey's test (compared with control REM), ${ }^{* *} p<0.01 ;{ }^{* * *} p<0.001$.

centage of the total REM sleep was $2.0 \%$ in the low REM sleep condition rat, $11.5 \%$ in the baseline REM sleep condition rat, and $20.1 \%$ in the high REM sleep condition rat. Thus, compared with the baseline or normal REM sleep condition rat, the low REM sleep condition rat had $82.60 \%$ less REM sleep, and the high REM sleep condition rat had $\sim 75 \%$ more REM sleep. The PKA activity data revealed that compared with the normal REM sleep condition, PKA activity increased during the high REM sleep condition and decreased during the low REM sleep condition in the PPT. However, in the mPRF, PKA activity decreased during the high REM sleep condition and increased during the low REM sleep condition. The trends of these PKA activity results are comple-

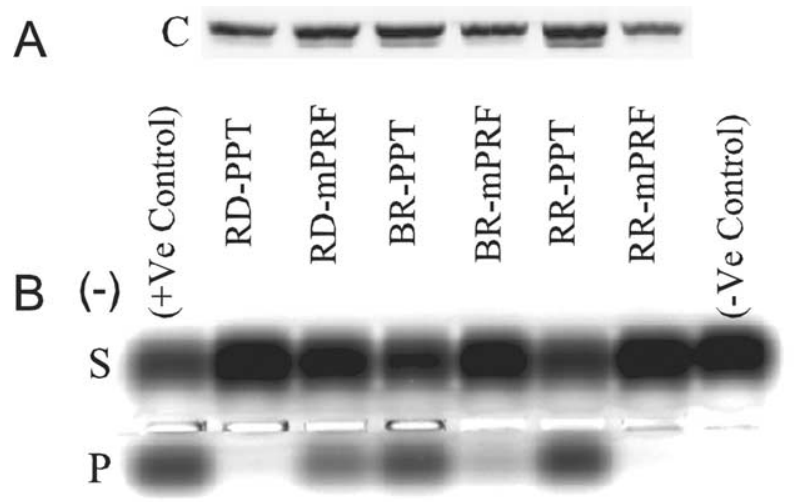

$(+)$
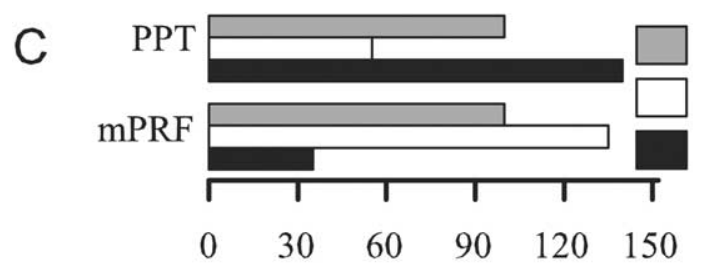

BR

$\mathrm{RD}$

RR

Level of C Expression

(\% Change From Control)

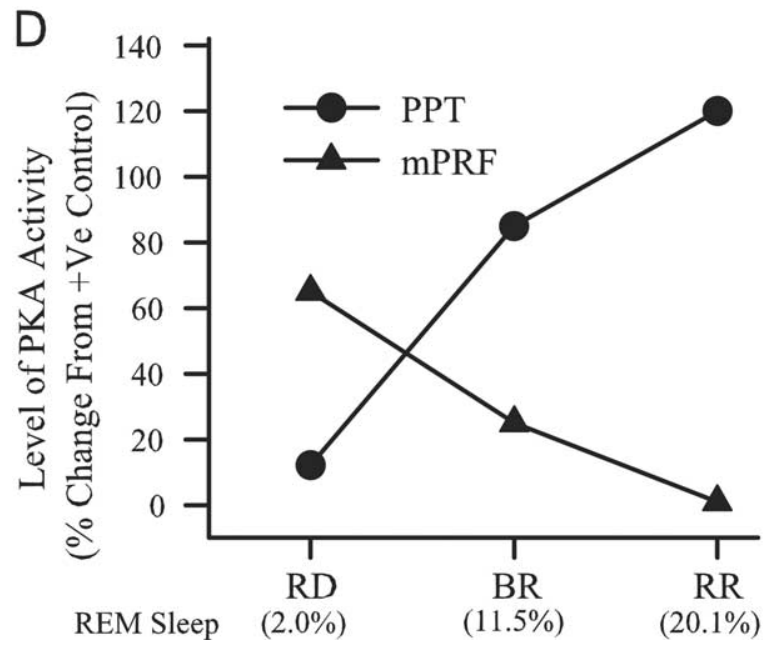

Figure 5. Effects of high and low REM sleep on the levels of PKA activity in the PPT and $m$ PRF. $A$, Western blots of the PKA catalytic subunit in the PPT and mPRF during three conditions: BR, $\mathrm{RD}$, and RR. Note that the PPT level of C increased during high REM sleep and decreased during low REM sleep, whereas in the mPRF, the level of $C$ decreased during high REM sleep and increased during low REM sleep. $B$, Agarose gel showing the activity profile of the PKA (free $C$ subunit of the PKA), visualized with UV light. The bottom band represents phosphorylated fluorescent-labeled Kemptide (P), and the top band represents the remaining unphosphorylated peptide (S). In the gel, phosphorylated product migrated toward the anode $(+)$, and unphosphorylated peptide migrated toward the cathode (-). + Ve Control, Purified catalytic subunit of PKA (20 ng); -Ve Control, no protein or enzyme added; RD-PPT, PPT of low REM sleep rat ( $2 \mu \mathrm{g}$ of protein); RD-mPRF, mPRF of low REM sleep rat ( $2 \mu \mathrm{g}$ of protein); BR-PPT, PPT of basal/control REM sleep rat ( $2 \mu \mathrm{g}$ of protein); BR-mPRF, $\mathrm{mPRF}$ of basal/control REM sleep rat ( $2 \mu \mathrm{g}$ of protein); RR-PPT, PPT of high REM sleep rat (2 $\mu \mathrm{g}$ of protein); RR-mPRF, mPRF of high REM sleep rat (2 $\mu \mathrm{g}$ of protein). Lane labels apply to both $\boldsymbol{A}$ and $\boldsymbol{B}$. C, Data from densitometric analysis of Western blots of PPT and mPRF during three conditions: BR, RD, RR. Data from densitometric analysis of Western blots in $A$ are expressed as a percentage of control (density in the BR-PPT and BR-mPRF, $100 \%$ values for the PPT and mPRF respectively). D, Quantitative profiles of the PKA activity in the PPT and $\mathrm{mPRF}$ of RD rats (2.0\% REM sleep), BR rats (11.5\% REM sleep), and RR rats (20.1\% REM sleep). To measure the level of PKA activities, initially, the OD of phosphorylated product in each lane of $\boldsymbol{B}$ was measured. Then, the $O D$ of the experimental lanes was expressed as a percentage change from the OD in the +Ve control lane. Note that in the PPT, PKA activity increased during high REM sleep and decreased during low REM sleep. Conversely, in the MPRF, PKA activity increased during low REM sleep and decreased during high REM sleep. 

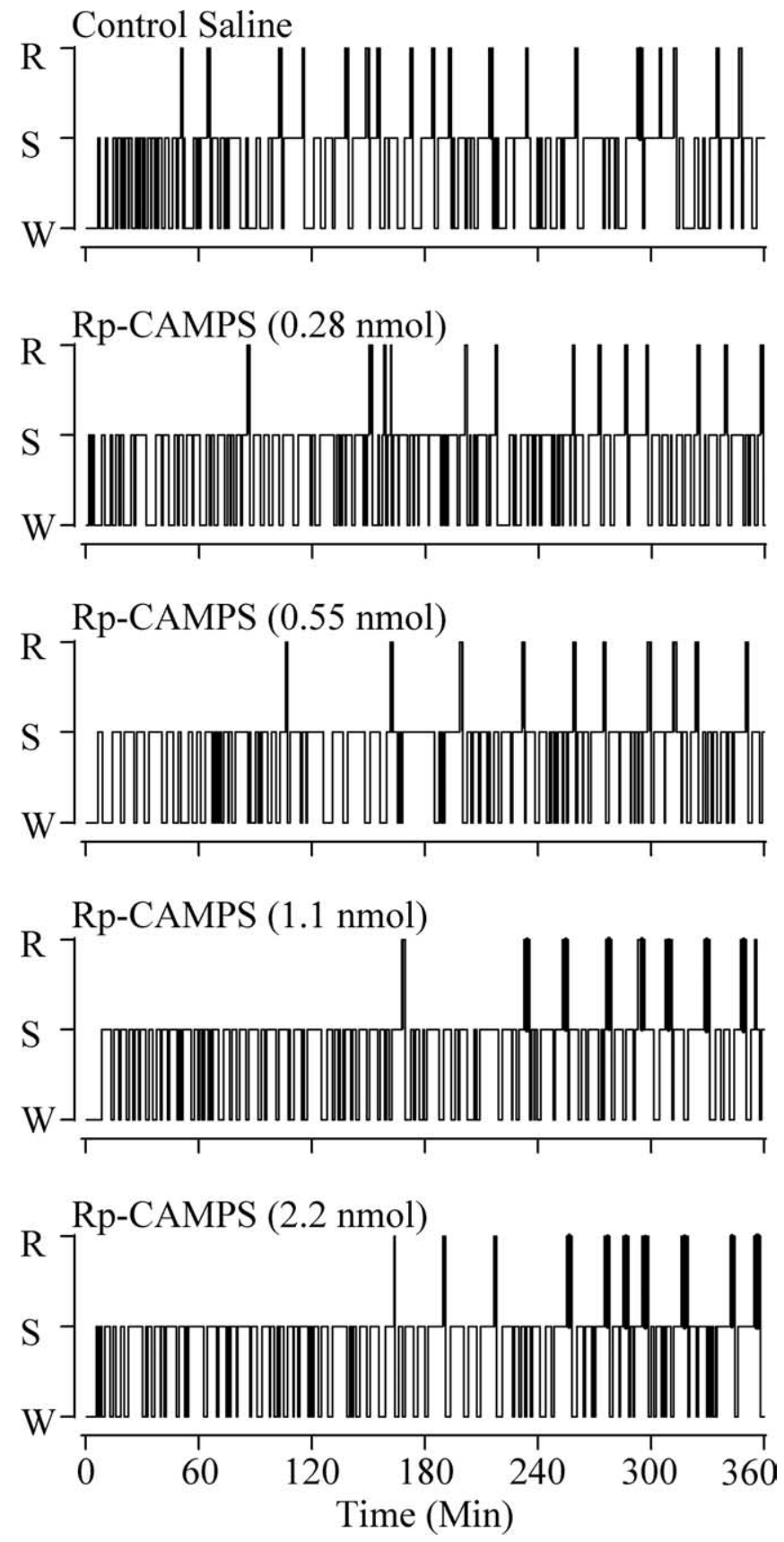

Figure 6. Examples to show the changes in sleep-wake architecture after unilateral microinjection of different doses of Rp-cAMPS into the PPT. These five hypnograms from five different rats plotted as step histograms plot the occurrence and duration of polygraphically defined W, SWS (S), and REM sleep (R) after control vehicle and four different doses of Rp-cAMPS. All microinjections were made at 10:00 A.M. (0 min) and were followed by $6 \mathrm{~h}$ of continuous recording.

mentary to the REM sleep-specific $\mathrm{PKA}_{\mathrm{C} \alpha}$ expression changes in the PPT and mPRF.

\section{Effects of Rp-cAMPS microinjection into the PPT on REM sleep}

The $6 \mathrm{~h}$ recording sessions (10:00 A.M. and 4:00 P.M.) containing representative sleep-wake architectures of five different rats immediately after unilateral microinjection of saline or one of four different doses of Rp-cAMPS into the PPT are illustrated in Figure 6. The figure shows a decreased latency for the first episode of

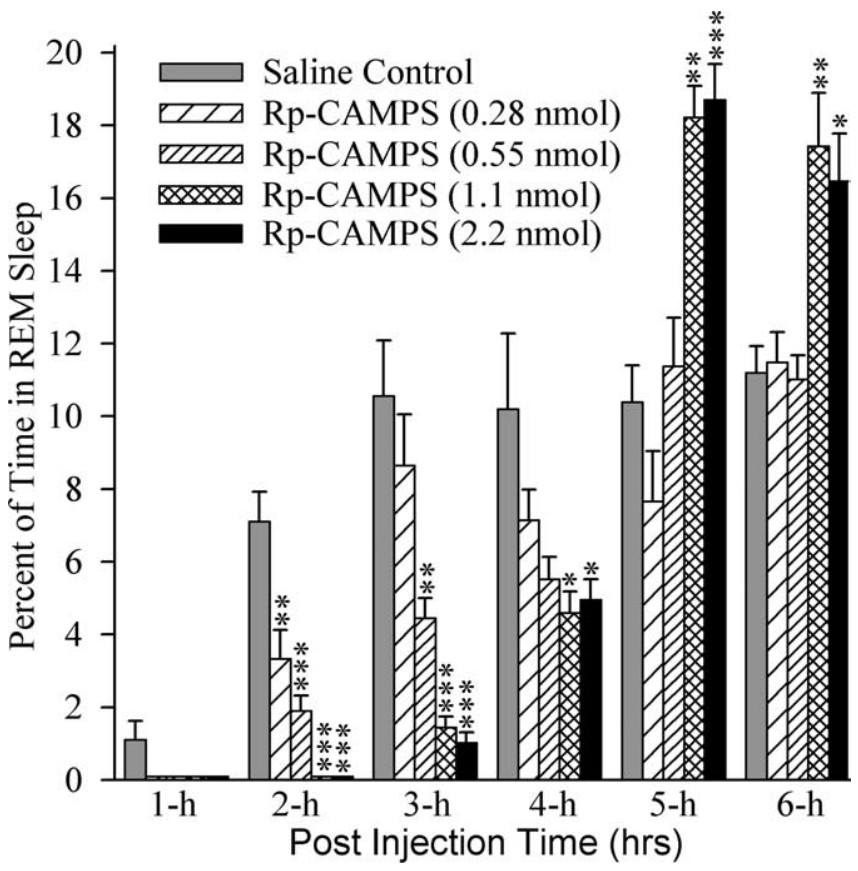

Figure 7. REM sleep after microinjections of control saline or one of four different doses of Rp-cAMPS into the PPT. Bars represent percentages (mean \pm SD) of REM sleep during each hour of the $6 \mathrm{~h}$ period after a single injection of saline control or $0.28,0.55,1.1$, and $2.2 \mathrm{nmol}$ of Rp-CAMPS. Note the dose-dependent decrease of REM sleep during the first $4 \mathrm{~h}$ after Rp-CAMPS microinjection. Also note the increased REM sleep during the fifth and sixth hours after 1.1 and $2.2 \mathrm{nmol}$ doses of Rp-cAMPS. This increased REM sleep after higher doses of Rp-CAMPS is a rebound effect. Asterisks indicate the levels of statistical significance (Scheffe's $F$ test) of the differences relative to control saline $\left({ }^{*} p<0.05 ;{ }^{* *} p<0.01\right.$; $\left.{ }^{* *} p<0.001\right)$.

REM sleep after unilateral microinjection of saline when compared with a unilateral microinjection of any one of the four different doses of Rp-cAMPS. During the first $4 \mathrm{~h}$, the number of REM sleep episodes after microinjection of Rp-cAMPS was lower compared with a microinjection of control saline. During the fifth and sixth hours, the number of REM sleep episodes after microinjection of Rp-cAMPS was similar to the number of REM sleep episodes after microinjection of control saline. However, in the 1.1 and $2.2 \mathrm{nmol}$ doses of Rp-cAMPS microinjections, the duration of REM sleep episodes was much longer than the saline control during the fifth and sixth hours of recordings.

Variations in the percentage of time spent in REM sleep after microinjection of the saline control or the different Rp-cAMPS doses are summarized in Figure 7. A two-way ANOVA on the total percentage of time spent in REM sleep indicated significant main effects of treatment $\left(F_{(4,30)}=8.34 ; p<0.001\right)$ and time $\left(F_{(5,130)}=179.11 ; p<0.001\right)$ and a significant treatment $\times$ time interaction $\left(F_{(20,150)}=14.41 ; p<0.001\right)$. The results of post hoc analysis (Scheffé's $F$ test) on the total percentage of time spent in REM sleep are presented in Figure 7 . During the first $4 \mathrm{~h}$, rats receiving a microinjection of $\mathrm{Rp}$-cAMPS exhibited a dosedependent decrease in the total percentage of time spent in REM sleep compared with post-control-injection recordings. The lowest dose $(0.28 \mathrm{nmol})$ of Rp-cAMPS reduced the total percentage of REM sleep significantly in the second hour. When this Rp-cAMPS dose was further increased to $0.55 \mathrm{nmol}$, the total percentage of REM sleep was significantly lower, lasting into the third hour. Microinjections of 1.1 and $2.2 \mathrm{nmol}$ doses of Rp-cAMPS suppressed REM sleep completely for the first $2 \mathrm{~h}$ after injection, with the total percentages of REM sleep remaining significantly lower in the third and fourth hours. In addition, 

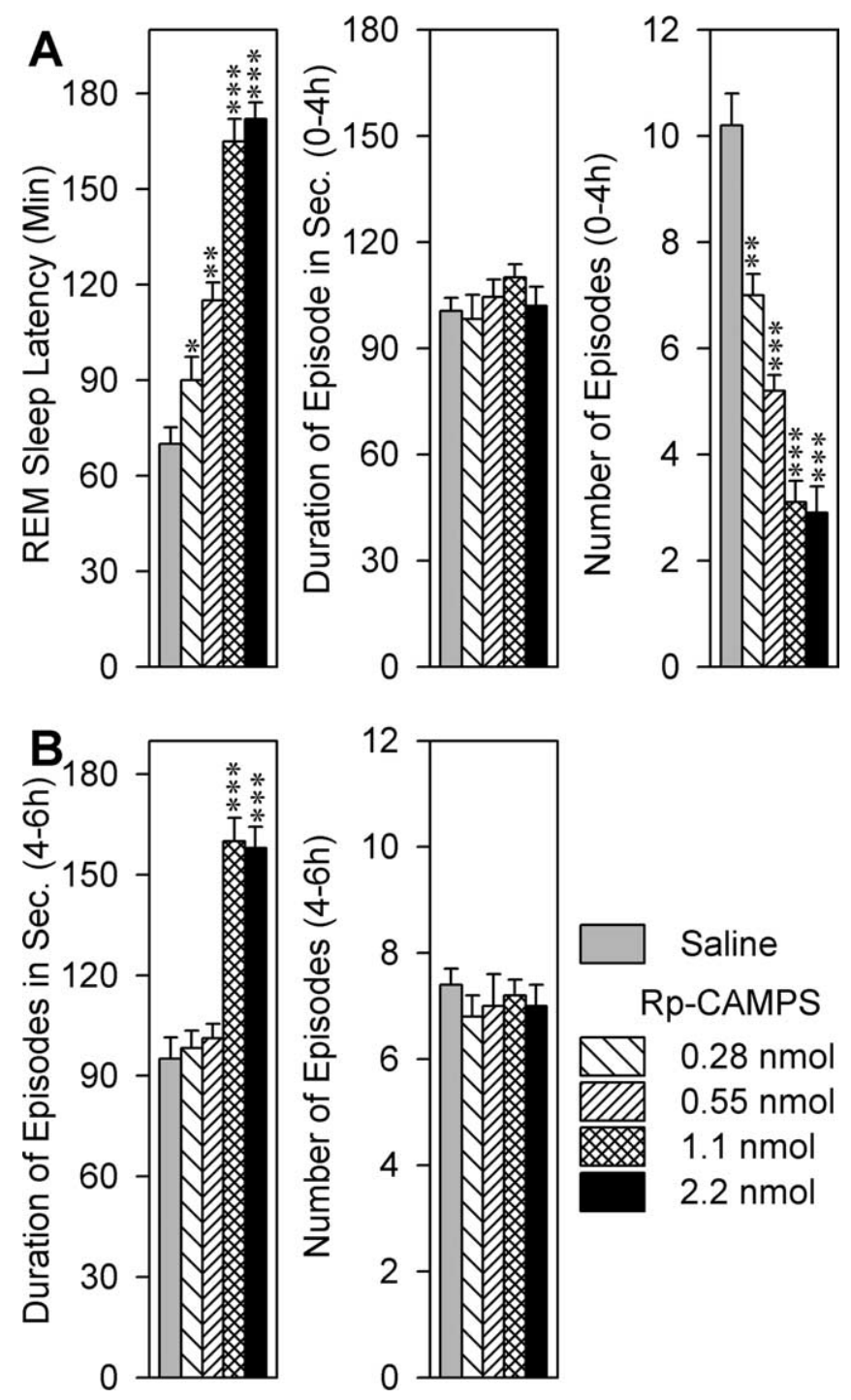

Figure 8. Effects on the latency, total number, and mean duration of REM sleep episodes observed after microinjection of saline or one of four different doses of Rp-CAMPS into the PPT. Data are presented as mean \pm SE. $\boldsymbol{A}$, Note that compared with the control saline, microinjections of Rp-cAMPS dose-dependently increased latency for the first episode of REM sleep and decreased the number of REM sleep episodes during the first $4 \mathrm{~h}(0-4 \mathrm{~h}) . \boldsymbol{B}$, Also note that during the last $2 \mathrm{~h}(4-6 \mathrm{~h})$ after microinjection of 1.1 and $2.2 \mathrm{nmol}$ Rp-CAMPS, the duration of REM sleep episodes increased. Asterisks indicate the levels of statistical significance (Scheffé's $F$ test) of the differences relative to control saline $\left({ }^{*} p<0.05 ;{ }^{* *} p<0.01 ;{ }^{* * *} p<0.001\right)$.

when compared with control injection, these two higher doses of Rp-cAMPS significantly increased the total percentage of REM sleep in the fifth and sixth hours after injection (Fig. 7).

Because Rp-cAMPS dose-dependently decreased the total percentage of REM sleep in all experimental groups during the first $4 \mathrm{~h}$ after injection, we first looked at the effects of different doses of Rp-cAMPS on latency, number, and duration of REM sleep episodes for this time period. The effects of different doses of Rp-cAMPS on latency, number, and duration of REM sleep episodes during the first $4 \mathrm{~h}$ are illustrated in Figure $8 \mathrm{~A}$. Onefactor ANOVAs and post hoc Scheffé's $F$ tests revealed that the reduction in REM sleep after microinjection of Rp-cAMPS was attributable to increased latency and decreased number of REM sleep episodes. During this first $4 \mathrm{~h}$ period, the duration of REM sleep episodes did not significantly change after microinjection of any one of the four doses of Rp-cAMPS (Fig. 8A). Next, we examined the increase in the total percentage of REM sleep during the fifth and sixth hours after microinjection of 1.1 and $2.2 \mathrm{nmol}$ doses of Rp-cAMPS. The results of Scheffé's $F$ tests revealed that this increase in the total amount of REM sleep in the fifth and sixth hours after 1.1 and $2.2 \mathrm{nmol}$ doses of Rp-cAMPS was attributable to increased duration of REM sleep episodes (Fig. $8 B$ ).

Because we are focusing mainly on the regulation of REM sleep, detailed results on the total percentages of W and SWS data are not presented here. However, it is worth mentioning that our two-way ANOVAs and post hoc Scheffé's F tests did not reveal any significant differences in the total percentages of W and SWS among groups that received microinjection of four different doses of Rp-cAMPS and control saline into the PPT. These results indicated that the microinjection of Rp-cAMPS into the PPT did not significantly change the total percentages of W and SWS.

\section{Discussion}

Neurotransmitters, hormones, and neuromodulators regulate many cellular functions by activating the ubiquitous cAMPdependent PKA system (Borrelli et al., 1992; Spaulding, 1993; Nestler and Greengard, 1994). Newly synthesized, extracellular neurotransmitter activation-dependent cAMP molecules bind to regulatory $(\mathrm{R})$ subunits on PKA holoenzymes (inactive form of PKA). When cAMP binds to the R subunits, it causes the holoenzyme to disaggregate and release its $\mathrm{C}$ subunits. The freed $\mathrm{C}$ subunits can then phosphorylate specific protein substrates in both the cytoplasm and nucleus. A major nuclear target for free $\mathrm{C}$ subunits is the cAMP response element (CRE)-binding protein (CREB) family, which binds to CRE genes. One of the most common means by which cells coordinate CAMP-mediated gene response is via the phosphorylation of CREB proteins, which alters the ability of the CREB proteins to form dimers and interact with CREs (for review, see Lohmann and Walter, 1984; Taylor et al., 1990; Spaulding, 1993). Thus, increased expression of C subunits is an indication that there is an increased demand for PKA activity to activate genes and ultimately to produce a behavioral response specific to that particular cell (Meinkoth et al., 1990). In contrast, additional $\mathrm{R}$ subunits would bind with free $\mathrm{C}$ subunits and ultimately reduce the activity of PKA activation-mediated cellular and behavioral response (Weber and Hilz, 1986; Spaulding, 1993).

Compared with the BR group, the total percentage of REM sleep during the last $2 \mathrm{~h}$ of experimental recording sessions was $77 \%$ lower in the RD group and $84 \%$ higher in the RR group. For the following reasons, we believe that the differences observed in the PKA subunit expressions between these three groups were a result of the differences in the total amount of time spent in REM sleep. First, the data show that the total amounts of time spent in $\mathrm{W}$ and SWS during the last $2 \mathrm{~h}$ of each experimental recording session were not significantly different. Second, continuous use of this selective REM sleep-deprivation protocol for a $6 \mathrm{~h}$ period does not cause any significant stress or change in motor behaviors (Datta et al., 2004). Finally, diurnal factors seem unlikely to have played a major role in the different levels of PKA subunit expression in different groups of rats because all 18 rats were killed at a fixed time of the day (at 2:02 P.M.).

Analysis of PKA subunit expression in the PPT revealed that, with higher amounts of REM sleep, the $\mathrm{C}$ subunit level increased, whereas RI and RII $\beta$ levels decreased. A simultaneous increase in levels of $\mathrm{C}$ subunits and decrease in levels of $\mathrm{R}$ subunits indicates that the active form of intracellular PKA is increased (Weber and Hilz, 1986; Meinkoth et al., 1990; Spaulding, 1993). Thus, the 
subunit expression data suggest that the availability of the active form of PKA was increased during increased REM sleep. Conversely, when animals had very small amounts of REM sleep, the PPT levels of C, RI, and RII $\beta$ subunits decreased. Reduced expression of these $C$ and $R$ subunits suggests that the availability of both the active and inactive forms of PKA is low. Consistent with our PKA subunit expression data, results of the present study also demonstrated that PKA activity in the PPT increased during high REM sleep and decreased during low REM sleep (Fig. 5). The results of our pharmacological study also demonstrated that the inhibition of cAMP-dependent PKA activity within the PPT suppressed REM sleep in a dose-dependent manner (Fig. 7). Together, the PKA subunit expression, PKA activity, and cAMPdependent PKA activity inhibition data indicate that increased activation of the PPT intracellular PKA system is involved in the generation of REM sleep. These molecular and pharmacological findings are consistent with previous single-cell recordings and pharmacological stimulation studies that have shown that activation of PPT cells is critical for the generation of REM sleep (ElMansari et al., 1989; Datta, 1995; Datta et al., 2001; Datta and Siwek, 2002; Ulloor et al., 2004).

Unlike in the PPT, the mPRF levels of $\mathrm{C}$ subunit expression decreased during high REM sleep, indicating that the active form of PKA is reduced. During low REM sleep, levels of C subunit expression increased, whereas levels of RII $\alpha$ and RII $\beta$ subunits decreased. These results suggest that availability of the active form of PKA is reduced in the MPRF during REM sleep (Weber and Hilz, 1986; Meinkoth et al., 1990; Spaulding, 1993). Because no other studies have measured sleep-dependent PKA subunit expression in the brain, these results could not be compared. However, one study reported that pharmacological activation of mPRF cAMP-dependent PKA system could block carbachol microinjection-induced REM sleep in the cat (Capece and Lydic, 1997). Thus, based on the subunit expression data of the current study and a previous pharmacological study in the cat (Capece and Lydic, 1997), it is reasonable to suggest that to generate REM sleep, cAMP-PKA activity is reduced in the mPRF. Indeed, PKA activity data of the present study also demonstrated that increased REM sleep is associated with decreased PKA activity (Fig. 5 ). The results of our PKA activity may resolve controversy regarding whether activation (Ahnaou et al., 1999) or inhibition (Marks and Birabil, 2000) of mPRF AC is involved in the generation of REM sleep.

Although it may not effect the interpretation of the present study, future technical advancement may supplement the interpretation of this study, for example, by adding the possible involvement of another brainstem nucleus, the laterodorsal tegmentum (LDT), and by specifying PKA activity to the cholinergic phenotypes of the PPT. Based on single-cell activity patterns, the LDT is also suspected to be involved in the regulation of REM sleep (Steriade and McCarley, 1990; Steriade et al., 1990; Datta, 1995; Maloney et al., 1999; Jones 2004). As in the PPT, it would be interesting to examine the relationship between the level of REM sleep and PKA subunit expression in the LDT. However, its small size and close proximity to the aqueduct did not allow examination of the LDT either pharmacologically or using existing molecular techniques. In this study, a selective inhibitor of cAMPdependent PKA activity was injected into the part of the PPT (pars compacta) in which the majority of cells is known to be cholinergic (Mesulam et al., 1983; Rye et al., 1987). Nonetheless, we acknowledge that if there are noncholinergic cells located within the targeted cholinergic cell groups, they will also be affected by the application of this drug. Similarly, it is possible that tissues from the PPT used to determine the expression of PKA subunits and to assay PKA activity contained not only cholinergic cells, but also some noncholinergic cells that may be present in the PPT (Ford et al., 1995).

To understand the specificity of REM sleep-dependent PKA subunit expression in the REM sleep-generating areas of the brain, we also measured the expression of these subunits in the mPFC and AHTh. These results show for the first time that during both high and low REM sleep, the levels of the $\mathrm{C}$ subunit decreased and the levels of the RI subunit increased in the mPFC. The current data suggest that during high and low levels of REM sleep, the levels of the active form of PKA are decreased in the mPFC (Weber and Hilz, 1986; Meinkoth et al., 1990; Spaulding, 1993). These results indicate that the PKA system in the mPFC may not be directly involved in the regulation of REM sleep. However, these results are consistent with neuroimaging studies that revealed decreased neuronal activity and metabolic rate of glucose in the human $\mathrm{mPFC}$ during both sleep deprivation and spontaneous REM sleep (Maquet et al., 1990, 1996; Thomas et al., 2000). Dysregulation of PKA signaling in the mPFC is known to disrupt executive functions in rats and monkeys (Ramos et al., 2003). Cognitive deficits caused by some neurodegenerative diseases are also suspected to be caused by the reduction of REM sleep (Prinz et al., 1982; Montplaisir et al., 1998). Thus, it could be suggested that sleep loss-induced deficits in executive functions observed in the human are attributable to the decreased PKA activity in the mPFC.

The results of this study show for the first time that during both high and low REM sleep periods, AHTh levels of RI and $\mathrm{RII} \beta$ subunits increase, but the level of the $\mathrm{C}$ subunit remains unchanged. Because increased levels of $\mathrm{R}$ subunits prevent activation of PKA by increasing the aggregation strength between $\mathrm{C}$ and R subunits (Weber and Hilz, 1986; Meinkoth et al., 1990; Spaulding, 1993), these results indicate that during high and low amounts of REM sleep, the availability of the active form of PKA is reduced. The reduced levels of active PKA in both REM sleep conditions suggests that the PKA system in the AHTh may not be involved in the regulation of REM sleep. This suggestion is in agreement with previous findings that indicated activation of AHTh is involved in the generation of SWS but not REM sleep (Nauta, 1946; Kaitin, 1984; Datta et al., 1988).

In conclusion, molecular, pharmacological, and behavioral data reported here suggest that the cAMP-dependent PKA signaling system in the PPT is activated to generate spontaneous REM sleep. This novel finding is critical for our complete understanding of the basic mechanisms in REM sleep generation.

\section{References}

Ahnaou A, Basille M, Gonzalez B, Vaudry H, Hamon M, Adrien J, Bourgin P (1999) Long-term enhancement of REM sleep by the pituitary adenylyl cyclase-activating polypeptide (PACAP) in the pontine reticular formation of rat. Eur J Neurosci 11:4051-4058.

Borrelli E, Montmayeur JP, Foulkes NS, Sassone-Corsi P (1992) Signal transduction and gene control: the cAMP pathway. Crit Rev Oncog 3:321-338.

Bradford M (1976) A rapid and sensitive method for the quantification of microgram quantities of protein utilizing the principle of protein dye binding. Anal Biochem 72:248-254.

Capece ML, Lydic R (1997) cAMP and protein kinase A modulate cholinergic rapid eye movement sleep generation. Am J Physiol 273: R1430-R1440.

Cook SA, Welch SP, Lichtman AH, Martin BR (1995) Evaluation of cAMP involvement in cannabinoid-induced antinociception. Life Sci 56:2049-2056. 
Couve A, Moss SJ, Pangalos MN (2000) GABA-B receptors: a new paradigm in G protein signaling. Mol Cell Neurosci 16:296-312.

Dalley JW, Cardinal RN, Robbins TW (2004) Prefrontal executive and cognitive functions in rodents: neural and neurochemical substrates. Neurosci Biobehav Rev 28:771-784.

Datta S (1995) Neuronal activity in the peribrachial area: relationship to behavioral state control. Neurosci Biobehav Rev 19:67-84.

Datta S (2000) Avoidance task training potentiates phasic pontine-wave density in the rat: a mechanism for sleep-dependent plasticity. J Neurosci 20:8607-8613.

Datta S (2002) Evidence that REM sleep is controlled by the activation of brainstem pedunculopontine tegmental kainate receptor. J Neurophysiol 87:1790-1798.

Datta S, Patterson EH (2003) Activation of phasic pontine-wave (P-wave): a mechanism of learning and memory processing. In: Sleep and brain plasticity (Maquet P, Smith C, Stickgold R, eds), pp 135-156. New York: Oxford UP.

Datta S, Prutzman SL (2005) Novel role of brain stem pedunculopontine tegmental adenylyl cyclase in the regulation of spontaneous REM sleep in the freely moving rat. J Neurophysiol 94:1928-1937.

Datta S, Siwek DF (2002) Single cell activity patterns of pedunculopontine tegmentum neurons across the sleep-wake cycle in the freely moving rats. J Neurosci Res 70:611-621.

Datta S, Kumar VM, Chhina GS, Singh B (1988) Interrelationship of thermal and sleep-wakefulness changes elicited from the medial preoptic area in rats. Exp Neurol 100:40-50.

Datta S, Spoley EE, Patterson EH (2001) Microinjection of glutamate into the pedunculopontine tegmentum induces REM sleep and wakefulness in the rat. Am J Physiol 280:R752-R759.

Datta S, Spoley EE, Mavanji VK, Patterson EH (2002) A novel action of pedunculopontine tegmental kainate receptors: a mechanism of REM sleep generation in the rat. Neuroscience 114:157-164.

Datta S, Mavanji V, Ulloor J, Patterson EH (2004) Activation of phasic pontine-wave generator prevents rapid eye movement sleep deprivationinduced learning impairment in the rat: a mechanism for sleepdependent plasticity. J Neurosci 24:1416-1427.

El-Mansari M, Sakai K, Jouvet M (1989) Unitary characteristics of presumptive cholinergic tegmental neurons during the sleep-waking cycle in freely moving cats. Exp Brain Res 76:519-529.

Ford B, Holmes CJ, Mainville L, Jones BE (1995) GABAergic neurons in the rat pontomesencephalic tegmentum: codistribution with cholinergic and other tegmental neurons projecting to the posterior lateral hypothalamus. J Comp Neurol 363:177-196.

Garcia-Rill E, Skinner RD, Miyazato H, Homma Y (2001) Pedunculopontine stimulation induces prolonged activation of pontine reticular neurons. Neuroscience 104:455-465.

Gilman AG (1987) G proteins: transducers of receptor-generated signals. Annu Rev Biochem 56:615-649.

Goldman-Rakic PS (1987) Circuitry of the primate prefrontal cortex and the regulation of behavior by representational memory. In: Handbook of physiology, the nervous system, higher functions of the brain (Plum F, ed), pp 373-417. Bethesda, MD: American Physiological Society.

Goueli S, Larson B, Hsiao K, Worzella T, Gallagher A, Mathews E (2004) High-throughput kinase screening using a universal luminescent kinase assay. Cell Notes 10:20-23.

Hobson JA, Pace-Schott EF (2002) The cognitive neuroscience of sleep: neuronal systems, consciousness and learning. Nat Rev Neurosci 3:679-693.

Jones BE (2004) Paradoxical REM sleep promoting and permitting neuronal networks. Arch Ital Biol 142:379-396.

Kaitin KI (1984) Preoptic area unit activity during sleep and wakefulness in the cat. Exp Neurol 83:347-357.

Laemmli UK (1970) Cleavage of structural proteins during the assembly of the head of bacteriophage T4. Nature 227:680-685.

Lohmann SM, Walter U (1984) Regulation of the cellular and subcellular concentrations and distribution of nucleotide-dependent protein kinases. Adv Cyclic Nucleotide Protein Phosphorylation Res 18:63-102.

Maquet P, Dive D, Salmon E, Sadzot B, Franco G, Poirrier R, von Frenckell R, Franck G (1990) Cerebral glucose utilization during sleep-wake cycle in man determined by positron emission tomography and [18F]2-fluoro-2deoxy-D-glucose method. Brain Res 513:136-143.

Maquet P, Peters JM, Aerts J, Delfiore G, Degueldre C, Luxen A, Franck G
(1996) Functional neuroanatomy of human rapid eye movement sleep and dreaming. Nature 383:163-166.

Marinissen MJ, Gutkind JS (2001) G-protein coupled receptors and signaling networks: emerging paradigms. Trends Pharmacol Sci 22:368-376.

Marks GA, Birabil CG (2000) Infusion of adenylyl cyclase inhibitor SQ22,536 into the medial pontine reticular formation of rats enhances rapid eye movement sleep. Neuroscience 98:311-315.

McCarley RW (2004) Mechanisms and models of REM sleep control. Arch Ital Biol 142:429-467.

Meinkoth JL, Ji Y, Taylor SS, Feramisco JR (1990) Dynamics of the distribution of cyclic AMP-dependent protein kinase in living cells. Proc Natl Acad Sci USA 87:9595-9599.

Mesulam MM, Mufson EJ, Wainer BH, Levey AI (1983) Central cholinergic pathways in the rat: an overview based on an alternative nomenclature (Ch1-Ch6). Neuroscience 10:1185-1201.

Montplaisir J, Petit D, Gauthier S, Gaudreau H, Decary A (1998) Sleep disturbances and EEG slowing in Alzheimer's disease. Sleep Res Online 1:147-151.

Nauta WJH (1946) Hypothalamic regulation of sleep in rats: an experimental study. J Neurophysiol 1:455-473.

Nestler EJ, Greengard P (1994) Protein phosphorylation and the regulation of neuronal function. In: Basic neurochemistry: molecular, cellular, and medical aspects (Siegel GS, Agranoff BW, Albers RW, Molinoff PB, eds), pp 449-474. Boston: Little Brown.

Pace-Schott EF, Hobson JA (2002) The neurobiology of sleep: genetics, cellular physiology and subcortical networks. Nat Rev Neurosci 3:591-605.

Paxinos G, Watson C (1997) The rat brain in stereotaxic coordinates. San Diego: Academic.

Prinz PN, Peskind ER, Vitaliano PP, Raskind MA, Eisdorfer C, Zemcuznikov N, Gerber CJ (1982) Sleep, EEG, and mental function changes in senile dementia of the Alzheimer's type. Neurobiol Aging 3:361-370.

Punch LJ, Self DW, Nestler EJ, Taylor JR (1997) Opposite modulation of opiate withdrawal behaviors on microinjection of a protein kinase A inhibitor versus activator into the locus coeruleus or periaqueductal gray. J Neurosci 17:8520-8527.

Ramos BP, Birnbaum SG, Lindenmayer I, Newton SS, Dumon RS, Arnsten AFT (2003) Dysregulation of protein kinase A signaling in the aged prefrontal cortex: new strategy for treating age-related cognitive decline. Neuron 40:835-845.

Rye DB, Saper CB, Lee HJ, Wainer BH (1987) Pedunculopontine tegmental nucleus of the rat: cytoarchitecture, cytochemistry, and some extrapyramidal connections of the mesopontine tegmentum. J Comp Neurol 259:483-528.

Sahir N, Mas C, Bourgeois F, Simonneau M, Evrard P, Gressens P (2001) Caffeine-induced telencephalic vesicle evagination in early postimplantation mouse embryos involves cAMP-dependent protein kinase (PKA) inhibition. Cereb Cortex 11:343-349.

Schafe GE, LeDoux JE (2000) Memory consolidation of auditory pavlovian fear conditioning requires protein synthesis and protein kinase $\mathrm{A}$ in the amygdala. J Neurosci 20:RC96(1-5).

Self DW, Nestler EJ (1995) Molecular mechanisms of drug reinforcement and addiction. Annu Rev Neurosci 18:463-495.

Self DW, Genova LM, Hope BT, Barnhart WJ, Spencer JJ, Nestler EJ (1998) Involvement of cAMP-dependent protein kinase in the nucleus accumbens in cocaine self-administration and relapse of cocaine-seeking behavior. J Neurosci 18:1848-1859.

Shi W-X, Bunney BS (1992) Roles of intracellular cAMP and protein kinase $A$ in the actions of dopamine and neurotensin on midbrain dopamine neurons. J Neurosci 12:2433-2438.

Sivilotti L, Nistri A (1991) GABA receptor mechanisms in the central nervous system. Prog Neurobiol 36:35-92.

Smith C (1995) Sleep states and memory processes. Behav Brain Res 69:137-145.

Spaulding SW (1993) The ways in which hormones change cAMPdependent protein kinase subunits, and how such changes affect cell behavior. Endocr Rev 14:632-650.

Steriade M, McCarley RW (1990) Brainstem control of wakefulness and sleep. New York: Plenum.

Steriade M, Datta S, Pare D, Oakson G, CurroDossi R (1990) Neuronal activities in brain-stem cholinergic nuclei related to tonic activation processes in thalamocortical systems. J Neurosci 10:2541-2559.

Taylor SS, Buechler JA, Yonemoto W (1990) cAMP-dependent protein ki- 
nase: framework for a diverse family of regulatory enzymes. Annu Rev Biochem 59:971-1005.

Thomas M, Sing H, Belenky G, Holcomb H, Mayberg H, Dannals R, Wagner Jr H, Thorne D, Popp K, Rowland L, Welsh A, Balwinski S, Redmond D (2000) Neural basis of alertness and cognitive performance impairments during sleepiness. I. Effects of $24 \mathrm{~h}$ of sleep deprivation on waking human regional brain activity. J Sleep Res 9:335-352.

Ulloor J, Mavanji V, Saha S, Siwek DF, Datta S (2004) Spontaneous REM sleep is modulated by the activation of the pedunculopontine tegmental GABA-B receptors in the freely moving rat. J Neurophysiol 91:1822-1831.

Van Haastert PJ, Van Driel R, Jastorff B, Baraniak J, Stec WJ, De Wit RJ (1984) Competitive cAMP antagonists for cAMP-receptor proteins. J Biol Chem 259:10020-10024.
Wang L-Y, Salter MW, MacDonald JF (1991) Regulation of kainate receptors by cAMP-dependent protein kinase and phosphatases. Science 253:1132-1135.

Wang L-Y, Taverna FA, Huang X-P, MacDonald JF, Hampson DR (1993) Phosphorylation and modulation of a kainate receptor (GluR6) by cAMP-dependent protein kainase. Science 259:1173-1175.

Weber W, Hilz H (1986) cAMP-dependent protein kinase I and II: divergent turnover of subunits. Biochemistry 25:5661-5667.

White D, Shultz J (1992) A novel method for non-radioactive assays of specific protein kinases. Promega Notes 35:11-17.

Zhang B, Veasey SC, Wood MA, Leng LZ, Kaminski C, Leight S, Abel T, Lee VM, Trojanowski JQ (2005) Impaired rapid eye movement sleep in the Tg2576 APP murine model of Alzheimer's disease with injury to pedunculopontine cholinergic neurons. Am J Pathol 167:1361-1369. 